\title{
Transitive responding in animals and humans: Exaptation rather than adaptation?
}

\author{
Juan D. Delius *, Martina Siemann \\ Allgemeine Psychologie, Universität Konstanz, D-78434 Konstanz, Germany
}

\begin{abstract}
In order to survive and reproduce, individual animals need to navigate through a multidimensional utility landscape in a near-optimal way. There is little doubt that the behaviourally more advanced species can bring cognitive competencies to bear on this difficult task. Among the cognitive abilities that are helpful in this context is transitive inference. This is typically the competency to derive the conclusion $\mathrm{B}>\mathrm{D}$ from the premises $\mathrm{A}>\mathrm{B}, \mathrm{B}>\mathrm{C}, \mathrm{C}>\mathrm{D}$ and $\mathrm{D}>\mathrm{E}$ that imply the series $\mathrm{A}>\mathrm{B}>\mathrm{C}>\mathrm{D}>\mathrm{E}$. In transitive inference tests used with humans, the letters stand for verbal items and the inequality symbols stand for a relational expression. To investigate analogous competencies in non-human animals a non-verbal form of the task is used. The premise pairs are converted into a multiple instrumental discrimination task $\mathrm{A}+\mathrm{B}-, \mathrm{B}+\mathrm{C}-, \mathrm{C}+\mathrm{D}-$ and $\mathrm{D}+\mathrm{E}-$, where the letters stand for non-verbal stimuli and the plus and minus symbols indicate that choices of the corresponding stimuli either lead to a reward or to a penalty. When these training pairs are adequately discriminated, transitive responding is tested with intermittent presentations of the novel pair $\mathrm{B} \circ \mathrm{D} \circ$, where the circles indicate that responses to the stimuli are not reinforced. Using variants of this basic conditioning task it has been shown that pigeons, rats, squirrel-monkeys, macaques, chimpanzees, young children, older children and adult humans commonly reveal transitive preferences for B over D. Several theories have been proposed to explain this transitive behaviour. The evidence supporting these various models is reviewed. It is shown that the learning of the premises normally brings about a choice and reinforcement biasing and balancing process that can account for transitive responding. It is argued that a very simple algebraic learning model can satisfactorily simulate many of the results obtained in transitivity experiments, including some produced by human subjects who in principle, could have been applying rational logical rules. It is demonstrated that a value transfer mechanism also assumed to explain transitive responding, is in fact, a real phenomenon based on classical conditioning. However, it is argued that it mostly plays a minor role in transitive responding. It is shown that the algebraic learning model can be easily converted into a neural network model exhibiting an equivalent performance. The model can also be modified to cope with the surprising finding that a proportion of human individuals and a few animals subjects learn to discriminate the premise pairs, but nevertheless fail to respond transitively to the conclusion pair. This modification can simulate the results of experiments using non-linear, in
\end{abstract}

\footnotetext{
* Corresponding author. Tel.: + 497531 883563; fax: + 497531 883184; e-mail: juan.delius@uni-konstanz.de
} 
particular circular, relational structures. The evolution of transitive responding is considered within the framework of ecosocial demands and neurobiological constraints. It is concluded that, in agreement with a preadaptation (exaptation) evolutionary origin, it seems to involve little beyond the capacity to learn multiple stimulus discriminations. (C) 1998 Elsevier Science B.V.

Keywords: Transitive responding; Transitive inference; Deductive reasoning; Learning models; Neural networks; Darwinian fitness; Utility landscapes; Pigeons; Rats; Primates; Humans

\section{Prologue}

Since Tinbergen's 'The Study of Instinct' (Tinbergen, 1951), it is fairly universally accepted that the behaviour of organisms must be understood as being the result of three sequential processes: phylogenesis, ontogenesis and physiogenesis. Here we wish to consider all of these processes as contributing to the emergence of a comparatively complex cognitive performance, transitive responding. From the point of view of behavioural ecology (Krebs and Davies, 1984), the underlying competence is concerned with the assumed regularities of the environment of animals and humans and the inter- and extrapolations that might be derivable from them. Many classes of objects, states and events belonging to both the inanimate and animate environment of organisms, seem to be characterised by ordered variations of one sort or another. Substrates may be freezing, temperate, warm, hot or burning; water may be close by, at some distance or far away; partners may be meek, indifferent, overbearing or overpowering; vegetation may be luscious green, dull olive, hay brown or arid yellow; patches may be bare, poor, medium, rich or abundant in prey. The characteristics of such gradients are often hard to define physically but many of them can nevertheless be presumed to be biologically vital. This is because such gradations often impinge in probabilistic but lawful ways on the survival and reproduction (fitness) of organisms (McFarland and Bösser, 1993). The gradients can abstractly be viewed as standing directly or indirectly for a web of selection pressure gradients that phylogenetically shape, among other characteristics, the behavioural dispositions of organisms. It is not unreasonable to think of the lifelong behaviour output of individual organisms as a navigation through these multidimensional, fitness-utility landscapes. The difficulty of this navigation has to do with the fact that more often than not, the crucial fitness-impinging features of these landscapes are not immediately available to the organism's perceptual apparatus and that their layout can not all possibly be apprehended through direct experience. Thus, for much of the navigation, the individual organism must rely, if it possesses the necessary sensory-neural equipment for it, on rather indirect cues that potentially allow implications about the fitness prospects that lay ahead. There is little doubt that humans (Homo sapiens) bring several reasoning competencies to bear on this task, transitive inferences being among them. But how about animals? Do they have comparable cognitive faculties for navigating through their life-long habitat space? The present paper first reports what is known about this and then proceeds to speculate about the evolutionary development of the relevant faculties. As the title question suggests, the issue is whether the competence of transitive responding possibly represents an adaptive reaction of some phyla to specific environmental demands.

The abstract image of a utility landscape serves well to introduce the actual problem that in a roundabout way triggered our laboratory's investigations of transitive responding behaviour in animals and humans. Many years ago A. Kacelnik (Oxford University) commented to the senior author that it seemed to him that flocks of starlings (Sturnus vulgaris) he watched feeding in meadows by the Isis were behaving as if they could deduce gradients of prey-density and as if they would optimise their foraging behaviour according to this information. Starlings arriving at a given field would apparently, first sample several closely neighbouring locations and then fly straight to a somewhat more distant site for a prolonged bout of obviously profitable foraging (cf. Dall and Cuthill, 1997). The problem was how 
to bring this hypothetical performance into the laboratory for a stringent experimental study. Delius (unpublished) made a preliminary attempt with pigeons (Columba livia) instead of starlings. An octagonal Skinner-box furnished with a pecking key on each wall and an automated grain hopper at the centre of the floor happened to be available. It was programmed so that pecks to each of the keys would yield differing durations of grain access. Either a clockwise or an anticlockwise increasing gradient of reward $(0-24 \mathrm{~s}$ of grain access) was randomly instituted for a given daily session. A dividing wall protruding into the chamber separated the keys corresponding to the best and the worst ends of the gradient. A trial ended and the next one began when a bird located the key yielding maximum reward.

Six hungry pigeons received several pretraining sessions with all keys illuminated and active until some of them appeared to have learned to locate the currently most rewarding key after a minimum number of key choices. Afterwards, only the two middle keys of the gradient were illuminated and active at the beginning of a session. The remaining keys would light up and be activated only when the pigeon had sampled the first two several times. It was expected that the pigeons would work out whether to turn right or left and accordingly, be able to seek out directly the key scheduled to be the most rewarding for that session. In spite of several weeks of work and several design adjustments, no such immediate and reliable choice behaviour emerged, even among the three pigeons that managed to produce a reasonably good pre-training performance. The evidence was that most birds seemed badly overtaxed by the task and that even the two that partly coped with the tests, very often resorted to the short-cut of comparing the yields of the two end keys of the gradient, i.e. those next to the dividing wall. In retrospect, we should have perhaps persisted longer and tried some obvious procedural improvements before giving up. Recent evidence concerning the processing of spatial stimulus arrangements by pigeons (Bingman, 1990; Wilkie and Willson, 1995) suggests that the problem we were setting them may not be totally beyond their intelligence.
What was suspected of the starlings and what was demanded of the pigeons, is a particular form of extrapolative induction. In intelligence tests for humans, this general competence is assessed with a variety of problems but often they involve the presentation of a brief series of items and the request to add an item. For example, given the sequence beginning $\mathrm{K}, \mathrm{L}, \mathrm{N}, \mathrm{R}$ what should the next letter be? However, on being told by a human cognition specialist, W. Matthäus (Bochum University) that children generally have more difficulty solving inductive problems than with solving deductive problems, we surmised that we were perhaps expecting too much cleverness of pigeons. He drew our attention to a deductive problem that has some superficial similarity with inductive extrapolation, that of transitive inference. Well known to logicians since antiquity, it was first studied empirically in 1921 by Piaget, the famous Swiss psychologist (but see also Burt, 1919). He presented children of different ages with verbal statements such as 'Celia is taller than Bella, Bella is taller than Anna' and then asked them questions such as 'Who is taller, Anna or Celia?' (A > B, B > C, A ? C). He reported that only children older than $\sim 6-7$ years could reliably solve this kind of problem. However, 50 years later, Bryant and Trabasso (1971) showed that transitive inference problems can already be mastered by 4 year old children, if one ensures that they have properly memorised the premises before being asked to draw conclusions. The task they used was largely non-verbal and concerned five differently coloured sticks A, B, C, D, E, that differed in length. The sticks were presented to the children in overlapping pairs: $\mathrm{AB}, \mathrm{BC}, \mathrm{CD}, \mathrm{DE}$. The children had to learn to point out within each pair which stick (the length differences not being shown) was the longer one. The training continued until they had reliably memorised the premise inequalities $\mathrm{A}>\mathrm{B}, \mathrm{B}>\mathrm{C}, \mathrm{C}>\mathrm{D}, \mathrm{D}>\mathrm{E}$. Then they were tested with the novel stick pairing BD, the length difference again not showing. Fouryear old children chose on $78 \%$ of the trials according the transitive conclusion $\mathrm{B}>\mathrm{D} ; 5$ and 6 year old children managed the better accuracies of 88 and $92 \%$, respectively. Given the puzzle that very young children, who are not yet thought 
capable of mastering the rules of deductive logic, can nevertheless adequately cope with a transitive inference problem, what about animals?

\section{Transitivity in pigeons and other animals}

In order to look for transitive responding in pigeons, von Fersen (1989) proceeded to convert the experimental procedure of Bryant and Trabasso into a fully averbal one in our laboratory. At the time we were not aware that other investigators had already developed such procedures for some other animal species (see below). The method that he devised was based on instrumentally conditioned stimulus discriminations. Five different visual shapes of equal size were arranged in overlapping pairs according to the scheme $\mathrm{A}+$ $\mathrm{B}-, \mathrm{B}+\mathrm{C}-, \mathrm{C}+\mathrm{D}-, \mathrm{D}+\mathrm{E}-$ and were successively presented, projected onto the two keys of a Skinner-box to mildly hungry pigeons (Fig. 1, top left). In fact, to control for any spontaneous shape preferences the pairs were presented with reversed reinforcement allocations $(\mathrm{A}-\mathrm{B}+, \ldots$, $\mathrm{D}-\mathrm{E}+)$ to three of the six pigeons used. However, since the performance of both groups turned out to be closely equivalent, the results were pooled and for simplicity, we adhere to the first notation style throughout. Both the right/left key allocation of the shapes composing the pairs and the presentation order of the four pairs on successive trials was randomised. Eight consecutive pecks to the key bearing the stimuli marked with + were rewarded with a few grains of millet delivered next to the relevant key, eight cumulative pecks to the stimuli marked with - were penalised with a brief period of darkness. However, after such an error the birds had a chance to choose again until they produced a correct choice on the particular pair of stimuli. The discrimination training was meant to convey the premise inequalities $\mathrm{A}>\mathrm{B}, \mathrm{B}>\mathrm{C}, \mathrm{C}>\mathrm{D}, \mathrm{D}>\mathrm{E}$, implying that the stimuli were ordered according to the linear hierarchy $\mathrm{A}>\mathrm{B}>\mathrm{C}>\mathrm{D}>\mathrm{E}$ allowing the logical conclusion $\mathrm{B}>\mathrm{D}$. Notice that whereas the end stimuli $\mathrm{A}$ and $\mathrm{E}$ were nominally scheduled to be either always rewarded or always penalised, the middle stimuli $\mathrm{B}, \mathrm{C}$ and $\mathrm{D}$, by being members of different pairs, were nominally scheduled to be equally often rewarded and penalised $(\mathrm{A}+, \mathrm{B} \pm$, $\mathrm{C} \pm, \mathrm{D} \pm, \mathrm{E}-)$. From a plain conditioning point of view, the shapes were thus intended to accord with an $\mathrm{A}>\mathrm{B}=\mathrm{C}=\mathrm{D}>\mathrm{E}$ pay-off relationship that would ensure a $\mathrm{B}=\mathrm{D}$ choice outcome.

Two of the six pigeons failed to achieve an average accuracy of $60 \%$ correct trials after 2500 training trials and were dismissed. The remaining four who did so, however, went on to reach a criterion of an average $80 \%$ correct trials within the next 2500 training trials and proceeded to a test phase. They received twelve presentations of the conclusion pair $\mathrm{B} \circ \mathrm{D}$ 。 interspersed randomly amongst some further trials with training pairs. These test trials were run under extinction conditions, that is the responses to both component
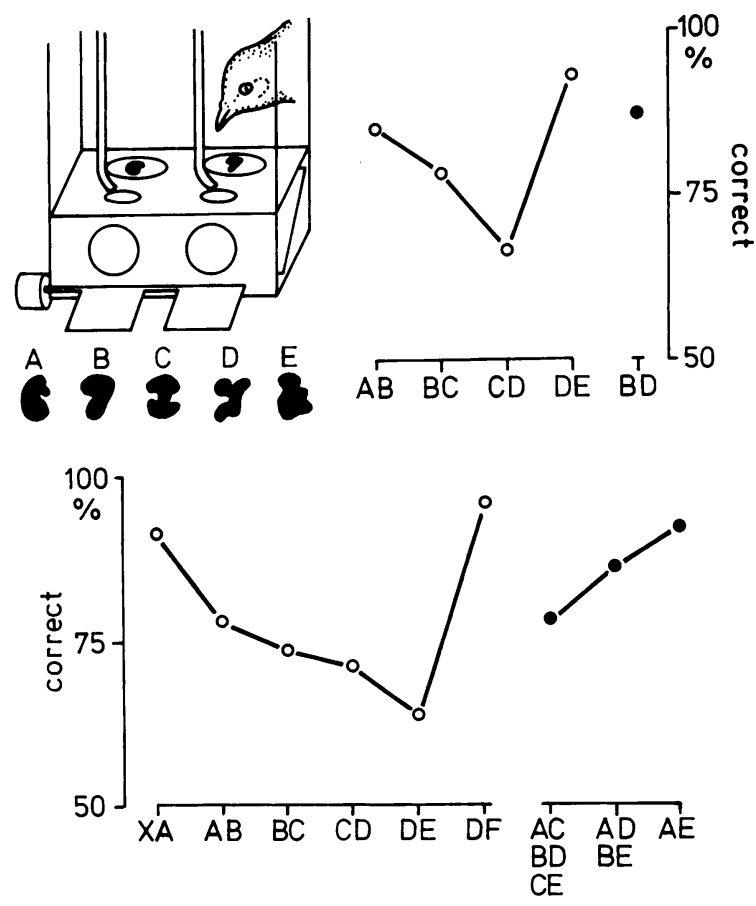

Fig. 1. Top left: Apparatus and stimuli employed to demonstrate transitive responding in pigeons. Top right: Discrimination performance on premise pairs (open circles) and conclusion pair (closed circles) obtained with the $\mathrm{A}+$ to $\mathrm{E}-$ series. Bottom: Discrimination performance on premise pairs and conclusion pairs obtained with the expanded $\mathrm{X}+$ to $\mathrm{F}-$ series (modified from von Fersen et al., 1991). 
stimuli being neither rewarded nor penalised. Each pigeon revealed a marked preference for stimulus $\mathrm{B}$, contrary to the plain conditioning prediction of an associative equality between the critical B and D stimuli. Averaged over the four subjects, this preference amounted to a highly significant $87.5 \%$ of the choices. It was even somewhat, though not significantly, superior to the accuracy achieved on the training pairs (average $81.7 \%$ ). The pigeons behaved as if they ranked the two stimuli according to a $\mathrm{B}>\mathrm{D}$ inequality, complying with the transitive conclusion $\mathrm{A}>\mathrm{B}>\mathrm{C}>$ $\mathrm{D}>\mathrm{E}$ implied by the reinforcement inequalities within the premise pairs (von Fersen et al., 1991). The performance during the test phase, both on the premise pairs and on the conclusion pair, is summarised in Fig. 1, top right. Note that the accuracies on the training pairs exhibit a concave trend. A similar end-anchoring effect has been repeatedly reported in connection with verbal transitivity results in humans (Breslow, 1981).

Von Fersen (1989) went on to retrain the four pigeons for almost another 7000 trials, with the series expanded to include seven stimulus shapes according to the scheme $\mathrm{X}+\mathrm{A}-, \mathrm{A}+\mathrm{B}-, \mathrm{B}+$ $\mathrm{C}-, \mathrm{C}+\mathrm{D}-, \mathrm{D}+\mathrm{E}-, \mathrm{E}+\mathrm{F}-$ until they reattained the $80 \%$ learning criterion. This made it possible to test them now with six valid conclusion pairs $\mathrm{A} \circ \mathrm{C} \circ, \mathrm{A} \circ \mathrm{D} \circ, \mathrm{A} \circ \mathrm{E} \circ, \mathrm{B} \circ \mathrm{D} \circ, \mathrm{B} \circ \mathrm{E} \circ, \mathrm{C} \circ \mathrm{E} \circ$. As before, pairs containing the end-stimuli $\mathrm{X}$ and $F$ were considered uninformative because these shapes had been either rewarded or penalised consistently during training. All the test pairs again yielded choice preferences that were consistent with the transitive responding hypothesis, the pigeons preferring on average the higher ranking stimuli of the various test pairs on $86.3 \%$ of the choices. Fig. 1, bottom shows that the training pairs yielded again an end-anchor effect, but also that the test pairs revealed an ordinal distance effect. That is, when pooled and ordered according to whether the stimuli of a pair bridged one $(\mathrm{A} \circ \mathrm{C} \circ, \mathrm{B} \circ \mathrm{D} \circ, \mathrm{C} \circ \mathrm{E} \circ)$, two $(\mathrm{A} \circ \mathrm{D} \circ, \mathrm{B} \circ \mathrm{E} \circ)$ or three $(\mathrm{A} \circ \mathrm{E} \circ)$ positions of the implied $\mathrm{X}>\mathrm{A}>\mathrm{B}>\mathrm{C}>$ $\mathrm{D}>\mathrm{E}>\mathrm{F}$ sequence, the transitive responding became more extreme. This effect is also often reported in connection with human verbal transitive inference results (Breslow, 1981).
Earlier studies report the occurrence of transitive responding in non-human primates. McGonigle and Chalmers (1977) trained squirrel-monkeys (Saimiri sciureus) using five differently coloured tins according to the same $\mathrm{A}+\mathrm{B}-, \mathrm{B}+\mathrm{C}-$, $\mathrm{C}+\mathrm{D}-, \mathrm{D}+\mathrm{E}-$ premise pair scheme. For half of the animals the tin marked with + was heavier and yielded a peanut when the monkeys shifted it, while the tin marked with - was lighter and yielded nothing when it was shifted. The other half of the animals were trained with a reversed reinforcement allocation scheme. But since, as with the pigeons, the two groups did not differ, the results are reported pooled. Incidentally, these, and some further authors that will be cited below, use the reversed $\mathrm{E}+$ to $\mathrm{A}-$ terminology to describe their results. For standardisation purposes we have consistently translated it to our $\mathrm{A}+$ to $\mathrm{E}-$ nomenclature. Only two tin weights were used so that the $\mathrm{A}>\mathrm{B}>\mathrm{C}>\mathrm{D}>\mathrm{E}$ sequence was again only implied by the within-pair reinforcement inequalities without there being a real end-to-end physical dimension. Seven of eight monkeys progressively learned the various training pairs up to a criterion of $90 \%$ correct choices in an obviously large, but not precisely specified, number of trials. When tested with equal-weight $\mathrm{B}+\mathrm{D}+$ conclusion pairs, they revealed a significant mean $90 \%$ preference for the B tin. A later study in which five of these squirrel-monkeys were briefly retrained and then re-tested actually yielded an even more pronounced B preference (McGonigle and Chalmers, 1992). Chalmers and McGonigle (1984), carried out much the same experiment with 6 year old children and found that they did not differ much in performance from the squirrel monkeys. In particular, they yielded $70 \%$ transitive choices in the $\mathrm{B}+\mathrm{D}+$ tests. Furthermore, monkeys and children showed comparable choice patterns in additional tests where they had to choose one item out of three offered simultaneously (e.g. $\mathrm{B}+\mathrm{C}+\mathrm{D}+, \mathrm{B}+\mathrm{D}+\mathrm{E}+$, $\mathrm{A}+\mathrm{C}+\mathrm{D}+$, etc.). Within the $\mathrm{B}+\mathrm{C}+\mathrm{D}+$ triads, for example, children and monkeys chose $\mathrm{B}$ in 57 and $61 \%, \mathrm{C}$ in 23 and $36 \%$ and $\mathrm{D}$ in 20 and $3 \%$ of the occasions, respectively. Notice that if obeying the rules of logic, at least the children should have exclusively chosen $\mathrm{B}$ within the $\mathrm{B}+$ $\mathrm{D}+$ and $\mathrm{B}+\mathrm{D}+\mathrm{C}+$ constellations. 
In a newer study, Treichler and Van Tilburg (1996) confronted six macaque monkeys (Maccaca mulatta) with two initially independent but concurrent five-item transitivity tasks $(\mathrm{A}+$ to $\mathrm{E}-; \mathrm{F}+$ to $\mathrm{J}-$ ). The stimuli were small junk objects which covered or did not cover a morsel of food. Both series yielded clear-cut transitive responding when the pairs $\mathrm{B}+\mathrm{D}-$ and $\mathrm{G}+\mathrm{I}-$ were first presented after the premise pairs had been learned. The two series were then linked by training the monkeys with an additional $\mathrm{E}+\mathrm{F}-$ pair. A large number of test pairs could be assembled from the resulting ten item long $\mathrm{A}+$ to $\mathrm{J}-$ series. All of these test pairs yielded above chance transitive responding results and furthermore, these results also evinced a strong ordinal distance effect much as von Fersen's pigeons did.

An earlier transitive responding study on primates was carried out by Gillan (1981) using chimpanzees (Pan troglodytes). He used six differently coloured containers as stimuli, which when opened by the animals, contained or did not contain a piece of food. Three chimpanzees were progressively trained with the standard $\mathrm{A}+$ to $\mathrm{E}-$ scheme of overlapping and differentially reinforced premise pairs. One animal reached an accuracy of $80 \%$ correct or better on all the premise pairs quite rapidly and chose transitively at a $80 \%$ correct level or better with conclusion test pairs. Another chimpanzee did so after considerable additional premise pair training but the third one did not ever yield reliable transitive responding. More recently Boysen et al. (1993) trained three chimpanzees progressively on a transitivity task using five differently coloured containers with the usual $\mathrm{A}+$ to $\mathrm{E}$ - premise pair scheme to an average $85 \%$ correct level in an unspecified number of trials. All three individuals showed a very strong (average 94\%) preference for B in B + $\mathrm{D}+$ and $\mathrm{B}-\mathrm{D}-$ tests. When retrained with the colours of the containers replaced by the Arabic numerals 1 to 5 as cues, the performance was generally less good and only one animal chose transitively at a significant level during the conclusion tests and this, despite the fact that all the chimpanzees had been other- wise and successfully trained to relate the numerals to physically corresponding quantities. With further numerosity and transitivity task experience, however, two animals eventually ended up responding transitively with the numerals as single cues.

Davis (1992a,b, 1996) reported transitive responding in rats (Rattus norvegicus). He trained them in an enclosure which, for a given trial, contained two odour-cued boxes, one of which gave access to sunflower seeds and another which did not. The rats successively learned to discriminate four odour pairs corresponding to the standard $\mathrm{A}+\mathrm{B}-, \ldots, \mathrm{D}+\mathrm{E}-$ scheme assembled using five different odorous substances. It was found that the rats had great difficulty with learning these training pairs. However, when the training was extended to include the additional odour pairs $\mathrm{A}+\mathrm{C}-, \mathrm{A}+$ $\mathrm{E}-, \mathrm{C}+\mathrm{E}-$, also conforming to the implied $\mathrm{A}>\mathrm{B}>\mathrm{C}>\mathrm{D}>\mathrm{E}$ linear inequality series, the animals did eventually learn to discriminate all training pairs. The additional pairs were presumably helpful because they underlined the special status of the end stimuli, A and E being now rewarded and penalised, respectively in three rather than only one of the training pairs. When they were then tested with the $\mathrm{B}+\mathrm{D}+$ and $\mathrm{B}-\mathrm{D}-$ test pairs, the rats chose transitively in more than $80 \%$ of the trials. Roberts and Phelps (1994) used an arena to train their rats on the usual four overlapping $\mathrm{A}+$ to $\mathrm{E}-$ premise pairs. The stimuli were odours that emanated from boxes that either did or did not allow the rats access to a chocolate reward. The pairs were either arranged according to a spatial linear layout consistent with the implied stimulus ordering, or according to an inconsistent, non-linear (random or circular) layout. All groups learned the premises but only the rats belonging to the group trained with the spatially linear arrangement exhibited transitive choices at a $75 \%$ level when tested with the $\mathrm{B}+\mathrm{D}+$ or $\mathrm{B}-\mathrm{D}-$ test odour pairs in a two-choice-arm maze. In short, a number of advanced vertebrate species seem capable of transitive responding when adequately trained with premise pairs and suitably tested with conclusion pairs. 


\section{Mentalistic model and behaviouristic theory}

The earlier studies on monkeys and apes by McGonigle and Chalmers (1977) and Gillan (1981) had suggested that both these species possessed the competence of transitive deduction to a degree comparable with that of at least younger humans. Since Von Fersen's pigeon results were closely equivalent to those of these primates, we were inclined to ascribe much the same mental skill to these birds. With regard to older humans, the transitivity competence has traditionally been attributed to their ability to apply the prescriptions of formal logic. Piaget $(1921,1953)$ in any case, believed that children only become capable of solving the transitivity syllogisms he used when they were old enough to have apprehended and internalised the rules of logic, that is, when they had reached the most advanced stage of mental development. However, accounts of reasoning based on a mental logic have lost favour with cognitive psychologists in recent times. It has turned out that too many empirical findings fail to match the rigidities of formal logic. Instead, accounts based on mental imagery metaphors have become popular in recent years (JohnsonLaird, 1983). In connection with transitive syllogisms, authors speak of a spatial paralogic (De Soto et al., 1965; Huttenlocher, 1968). Paralogical models assume that, based on the premises, subjects construct a spatial representation of the items rankings in their visual memory (Trabasso and Riley, 1975, Evans et al., 1993). When faced with the conclusion pair, the subjects are thought to turn their visual attention, or mind's eye (compare Kosslyn et al., 1994) to this imaginary lineup and work out what stimulus they must choose. When suitably developed, this mental representation model can account for a number of results associated with transitive responding tasks, including most notably, the ordinal distance effect (see above) which is hard to explain in terms of formal logic.

Impressed by the excellent spatial abilities of pigeons (Spetch, 1990; Wilkie et al., 1996) we were inclined to assume that von Fersen's birds might have proceeded in a similar manner. During training they had perhaps built up a memorial repre- sentation of the stimulus shapes analogous to an $\mathrm{A}>\mathrm{B}>\mathrm{C}>\mathrm{D}>\mathrm{E}$ image and had then simply referred to the imaginary size difference $\mathrm{B}>\mathrm{D}$ when assessing how to respond to the conclusion pair. However, in assuming this, we were ignoring a subsidiary result. Von Fersen had successfully trained and tested four additional pigeons using the same procedure detailed in the previous section, but with the relevant stimulus shapes diminishing in physical size going from A to E. For these birds there was, therefore, both a ranking based on the real size of the stimuli through the sequence and a ranking implied by the reinforcement allocations within the premise pairs. This had been specifically done to assist them with the formation of the above hypothetical mental line. Von Fersen had expected this group of pigeons to learn the premise pairs faster and to solve the conclusion pairs better than had the previously reported group with all its stimuli of equal size. However, in the end, they did not differ at all from the latter in either respect (von Fersen, 1989; Emmerton and Delius, 1993). This occurred in spite of the fact that, in separate tests with pairs of different-sized, novel stimuli, the same group of pigeons had actually shown some evidence of discriminating according to the relative sizes of the stimuli (Mackintosh, 1974; von Fersen, 1989: size transposition). The finding that the size dimension did not aid transitive responding should have made us suspicious of the mental line model as an account of transitive inference as far as pigeons were concerned, but at the time it did not do so.

Shortly afterwards, however, a visitor to our laboratory, J.E.R. Staddon (Duke University) expressed doubts about this hard-to-formalise imagery theory and thought that, since conditioning procedures had been used to train the birds on the premise pairs, there had to be a more behaviouristic account for their transitive responding on the conclusion pairs. He eventually proposed a theoretical account that was based on conditioning mechanisms. A final, honed-down version of this so-called value transfer theory was presented in the von Fersen et al. (1991) paper. The model was based on the conventional notion that discrimination learning arises through the circum- 
stance that the response-eliciting-values accruing to the stimuli, change as a consequence of the rewards that are contingent upon responses to them. Thus, given a training pair $\mathrm{X}+\mathrm{Y}-$, the rewarded choice of stimulus $\mathrm{X}+$ increases its value $V_{x}$ by some amount, while the unrewarded choice of $\mathrm{Y}-$ leaves $V_{y}$ unchanged. Applying this to the training scheme $\mathrm{A}+\mathrm{B}-, \mathrm{B}+\mathrm{C}-, \mathrm{C}+$ $\mathrm{D}-, \mathrm{D}+\mathrm{E}-$, stimulus $\mathrm{A}$, scheduled always to be rewarded, eventually accumulates a high associative value, say $V_{a}=k$. Stimulus $\mathrm{E}$, scheduled never to be rewarded, retains a low value, say $V_{\mathrm{e}}=0$. The middle stimuli $\mathrm{B}, \mathrm{C}$ and $\mathrm{D}$, scheduled to be evenly rewarded and not rewarded across their occurrences, accumulate an intermediate value, say $V_{\mathrm{b}}=V_{\mathrm{c}}=V_{\mathrm{d}}=k / 2$. Then, less orthodoxly, the theory assumes that when stimulus $\mathrm{X}+$ is chosen and rewarded, a small fraction of its value transfers instantly to its simultaneously present companion $\mathrm{Y}-$ according to the update function $V_{y} \leftarrow \alpha * V_{x}+V_{y}$. Here and later the symbol $\leftarrow$ indicates that the variable to its left takes the value of the expression to its right. Specifying a $0<\alpha<0.5$ transfer parameter, this update directly yields an orderly descending series of stimulus values. With $k=2$ and $\alpha=0.1$, for example, the values for the series mentioned above come out as $V_{\mathrm{a}}=2.00, V_{\mathrm{b}}=1.20, V_{\mathrm{c}}=1.12, V_{\mathrm{d}}=1.11$ and $V_{\mathrm{e}}=0.11$. The subsequent test preference for $\mathrm{B}$ over $\mathrm{D}$ during conclusion tests is obviously explained by the $V_{\mathrm{b}}>V_{\mathrm{d}}$ inequality that arises through the transfer mechanism.

The value transfer account can hardly be accused of being mentalistic but the reader should notice that it nevertheless has some commonality with the mental line hypothesis. It assumes that some neural, not merely mental, equivalents of graded associative values are acquired during premise learning, which effectively is a memory representation that orders the corresponding stimuli on a magnitude dimension. Also, the value transfer postulated was a largely ad-hoc theoretical construct when the model was proposed as an explanation of transitive responding. Later in this review we will report some recent evidence for the real existence of a value transfer mechanism much like that conceived by von Fersen et al., but in the meantime we proceed to argue that, somewhat disappointingly, it is unlikely to play any decisive role in bringing about transitive responding with the transitivity conditioning designs described in the previous sections.

\section{Reconsidering and exploring}

Because all four pairs were presented equally often, the $\mathrm{A}+\mathrm{B}-, \mathrm{B}+\mathrm{C}-, \mathrm{C}+\mathrm{D}-, \mathrm{D}+\mathrm{E}-$ training scheme used in von Fersen's (1989) experiment was thought to ensure that both $\mathrm{B}$ and $\mathrm{D}$ were each as often rewarded $(50 \%)$ as penalised $(50 \%)$ during their training. The reward to penalty reinforcement quotients of the critical stimuli B an $\mathrm{D}$ were thus assumed to be both $R_{\mathrm{b}}=R_{\mathrm{d}}=50 /$ $50=1$. Since these reinforcement quotients could be imagined to relate with the associative, response eliciting values of these stimuli (we return to this issue later) they implied a stimulus value equality $V_{\mathrm{b}}=V_{\mathrm{d}}$. From such a straightforward conditioning point of view, any transitive preference for stimulus $\mathrm{B}$ within the test pair $\mathrm{B} \circ \mathrm{D}$ 。 would clearly require some special explanation. However, a re-examination of the pigeons training pair performance at the time of the test phase eventually revealed that the basic equality assumption was not really warranted. At this final stage, at any rate, the training pairs $\mathrm{A}+\mathrm{B}-$, $\mathrm{B}+\mathrm{C}-, \mathrm{C}+\mathrm{D}-$ and $\mathrm{D}+\mathrm{E}-$ had in fact yielded 88, 78, 67 and 94\% mean correct choices, respectively. These percentages index the rewarded choices of the stimuli A, B, C, and D, but the scores conversely also specify that $12,22,33$ and $6 \%$ penalised choices of the stimuli B, C, D and $\mathrm{E}$ had occurred. The reward/penalty ratios for the stimuli B and D that operated at the time of $\mathrm{B} \circ \mathrm{D} \circ$ testing were thus factually $R_{\mathrm{b}}=78 / 12=$ 6.5 and $R_{\mathrm{d}}=94 / 33=2.8$. Obviously, these ratios do not equal 1 and clearly do not support the original $V_{\mathrm{b}}=V_{\mathrm{d}}$ equality assumption. Rather, they suggest a $V_{\mathrm{b}}>V_{\mathrm{d}}$ inequality which immediately explains the pigeons strong preference for $\mathrm{B}$ in the $\mathrm{B} \circ \mathrm{D}$ 。 tests.

In fact, because von Fersen used a correction procedure that ensured that the presentation of a given training pair always ended with a correct, rewarded choice, the above calculations are not 
entirely precise (Couvillon and Bitterman, 1992). It can be shown, however, that a more complex quotient computation that takes the effect of this procedure fully into account, produces an even stronger advantage for stimulus B. This remark, incidentally, also applies to our next experiment described below. Wynne (1997) has recently reported transitive responding results in pigeons arising from an experiment that did not involve such a correction procedure, but that otherwise did not differ by much in design from that of von Fersen's (1989) experiment. The data presented shows that the acquisition of the premise pair discriminations is markedly impaired by omitting the procedure. Undoubtedly this is so because without such procedure, pigeons are prone to adopt a non-discriminatory strategy associated with a persistent either left or right key preference that yields a non-optimal, but effortless, 0.5 reinforcement quotient across all the stimuli.

Returning to the previous argument, what had happened was that we, and obviously several colleagues before us, had only thought of the scheduled reinforcements but forgotten about the effect that these would have on the subjects choice behaviour. This is a peculiar oversight because particularly in connection with the extensive research on the relative preferences for differing operant reinforcement schedules (matching law: Herrnstein, 1961), the frequent disagreement between reinforcement scheduled and reinforcements obtained is more than well known (De Villiers, 1977). Obviously, the factual reinforcement ratios for a given stimulus are as much the product of the scheduled reinforcements as they are of the choice behaviour. The same argument, incidentally, also applies to the results of Von Fersen's $\mathrm{X}$ to $\mathrm{F}$ series and probably also to many of the non-verbal transitive responding results reported by other authors. Sometimes matters are complicated by the use of an often poorly documented non-randomly sequenced, unequal number of training pair presentations. That at least the latter factor can importantly affect the effective reward to penalty quotients of the critical stimuli is demonstrated next.

A closer analysis revealed that the reinforcement ratio inequality $R_{\mathrm{b}}>R_{\mathrm{d}}$ obtaining in von
Fersen et al.'s (1991) experiment was a consequence of the previously discussed end-anchor effect affecting the percentage accuracies of the training pairs $\left(P_{\mathrm{ab}}>P_{\mathrm{bc}}\right.$ and $P_{\mathrm{cd}}<P_{\mathrm{de}}$; Siemann et al., 1996a). This effect in turn was due to the fact that the end pairs, by uniquely including either a consistently rewarded or a consistently penalised stimulus, were easier to learn for the subjects than the middle pairs, which consisted exclusively of partly rewarded, partly penalised stimuli (see also later). What would happen, however, if the premise training were modified so as to prevent the emergence of any substantial end-anchor effect? Because von Fersen's pigeons had been slow to learn the premise pairs, Siemann et al. (1996b) turned to a new training and testing procedure that was expected to be more efficient in this respect. The pigeons were trained with the usual $\mathrm{A}+\mathrm{B}-, \mathrm{B}+\mathrm{C}-, \mathrm{C}+\mathrm{D}-$ and $\mathrm{D}+\mathrm{E}-$ pairs but the stimuli were five types of grit differing in colour and structure. Of the two grits offered in adjacent plastic cups to the hungry pigeons, the + grit concealed a single maize or pea grain while the - grit did not hide anything (Fig. 2, left). Choices were defined by the grit which the pigeon pecked first. The relative presentation frequencies of the four training pairs was adjusted such that those yielding poorer discrimination were shown relatively more often than those yielding better discrimination. When training was complete the $4 \times \mathrm{A}+\mathrm{B}-, 6 \times \mathrm{B}+\mathrm{C}-$, $7 \times \mathrm{C}+\mathrm{D}-, 1 \times \mathrm{D}+\mathrm{E}-$ presentation proportions selected, yielded a quite similar discrimination performance across the four premise pairs, which was thus practically free from an end-anchor effect (Fig. 2, right). At first sight, the percent choices for the various premise pairs appeared to indicate reward/penalty quotients of $R_{\mathrm{b}}=90 / 18=5.0$ and of $R_{\mathrm{d}}=95 / 5=19.0$. These would imply a marked $V_{\mathrm{d}}>V_{\mathrm{b}}$ inequality, predicting an antitransitive $\mathrm{D}>\mathrm{B}$ preference, contrary to the transitive one obtained in the Von Fersen's original experiment. However, the present pigeons also showed a strong preference for grit B (91\% choices) over grit D when confronted with the grainless $\mathrm{B}-\mathrm{D}-$ pair. The result seemed to suggest that there was more to the pigeons transitive choosing than the obtained re- 


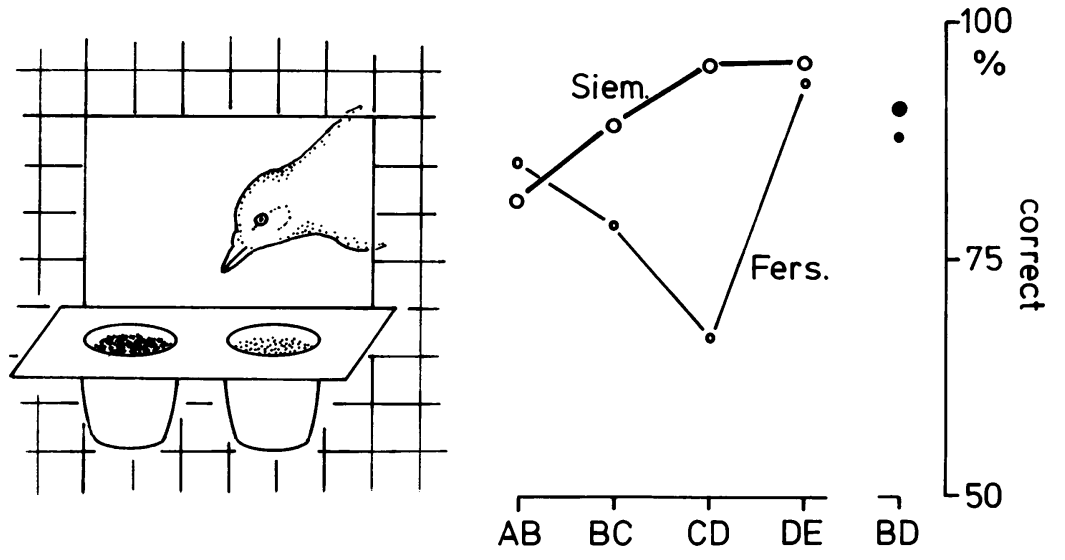

Fig. 2. Left: Grain-among-grit procedure used to demonstrate transitive responding in pigeons. Right: Discrimination performance on training pairs and test pair. The equivalent data of von Fersen et al. (1991) are included for comparison (modified from Siemann et al., 1996b).

inforcement quotients and the consequent values attached to the stimuli. However, the reinforcement quotients computed above did not take into account the varying relative frequencies with which the training pairs were being presented. When recalculated in accordance with the pair presentation proportions 4:6:7:1 listed earlier, the true reinforcement quotients were found to amount to $R_{\mathrm{b}}=(90 * 6) /(18 * 4)=7.5$ and $R_{\mathrm{d}}=$ $(95 * 1) /(5 * 7)=2.7$. This implied that after all, a $V_{\mathrm{b}}>V_{\mathrm{d}}$ inequality was also operative in this experiment and that there was no need to appeal to anything unusual to explain the pigeons preference for B during tests. The message, often ignored, is that a training of all the premise pairs up to a comparable accuracy level (same criterion, for example) does not necessarily mean that the critical conclusion stimuli have collected similar reinforcement scores.

We have assumed that when a pigeon chooses stimulus $\mathrm{X}$ in preference to stimulus $\mathrm{Y}$, it does so based on their values $V_{x}$ and $V_{y}$ that are some monotonic function of the $R_{x}$ and $R_{y}$ reinforcement ratios. The equation $P_{x y}=V_{x} * 100 /\left(V_{x}+\right.$ $V_{y}$ ) could be a simple quantitative rule determining the percentage choices of $\mathrm{X}$ rather than Y, based on such stimulus values (Luce, 1959). If substantially correct, this choice function allows one to estimate relative values for the stimuli on the basis of the empirical percent choices obtained with the four training pairs. To begin with, some arbitrary value needs to be assigned to one of the end stimuli, for example E, the actual value chosen being totally immaterial for the final result that is of interest. The relative value of stimulus $\mathrm{D}$ can then be derived from the actually observed choice percent $P_{\text {de }}$, using the expression $V_{\mathrm{d}}=P_{\mathrm{de}} * V_{\mathrm{e}} /\left(100-P_{\mathrm{de}}\right)$, a rearrangement and specification of the above choice equation. Entering for example Von Fersen's $P_{\mathrm{de}}=94 \%$ result and setting $V_{\mathrm{e}}=0.1$, one obtains $V_{\mathrm{d}}=94 * 0.1 /(100-94)=1.5$. The value $V_{\mathrm{d}}$ thus obtained, is then used analogously to calculate $V_{\mathrm{c}}=P_{\mathrm{cd}} * V_{\mathrm{d}} / 100-P_{\mathrm{cd}}$, and so forth for $V_{\mathrm{b}}$ and $V_{\mathrm{a}}$ using the remaining $P_{\mathrm{cd}}=67 \%, P_{\mathrm{bc}}=78 \%$ and $P_{\mathrm{ab}}=88 \%$ results. Once these relative values $V_{\mathrm{e}}$ to $V_{\mathrm{a}}$ for the stimuli E to A have been numerically determined in this way, the expected choice percents for the test pairs $\mathrm{B} \circ \mathrm{D} \circ$ can be calculated by inserting the derived values $V_{\mathrm{b}}=10.6$ and $V_{\mathrm{d}}=$ 1.5 into the choice equation $P_{\mathrm{bd}}=V_{\mathrm{b}} * 100 /\left(V_{\mathrm{b}}+\right.$ $V_{\mathrm{d}}$ ). This predicts a $87.6 \%$ preference for $\mathrm{B}$, which corresponds to an observed choice of $87.5 \%$, yielding a remarkably close fit.

It shows that a very minimal model based on stimulus values derived from the actual performance on the training pairs via a simple percent choice function is in fact sufficient to predict transitive responding for the $\mathrm{B} \circ \mathrm{D} \circ$ test pair. The same kind of derivation also produces good 
matches with the test results of the grit experiment described above (Siemann et al., 1996b) and quite likely with many other transitive responding results. Note however, that all the derivation model does is that, when a typically successful training pair result is extant, it makes it possible to predict the typical transitive test pair result. Indeed, it is likely to cope equally well with the transitivities observed with choices among stimuli for which a given species has spontaneous preferences, i.e. those that may be of innate origin or which at least have not been expressly trained. Most of the many other, generally more complex choice models that have been proposed principally within this last context will, incidentally, also predict transitive responding when the premise pairs yield reasonable discrimination accuracies (Dawkins, 1969; Coombs et al., 1970; McGonigle and Chalmers, 1977). But we now want to go a step further with the modelling effort and try also to account for the performance on training pairs on the basis of conventional conditioning and choice principles.

\section{A complete but simple theory}

When the previously mentioned value transfer theory of transitive responding was published (von Fersen et al., 1991) it met with immediate criticism. Couvillon and Bitterman (1992) pointed out that it appealed to an undocumented transfer mechanism and furthermore, that it did so quite unnecessarily. These authors showed instead that a conventional conditioning theory (Bush and Mosteller, 1951), combined with a somewhat elaborate choice function, produced a remarkably accurate prediction of von Fersen's pigeon results. Wynne et al. (1992) drew attention to the fact that similarly conventional, but even more elementary, conditioning theories would also predict transitive responding results. This is because all the models they listed yield a kind of intrinsic value transfer that renders superfluous an explicit transfer mechanism of the sort that von Fersen et al. (1991) had assumed. An exceedingly simple model of the former kind has since proven to simulate successfully a variety of transitive responding results (Werner et al., 1992; Siemann and Delius, 1993,
1997). It is based on a learning operator postulated by Luce (1959) and is hence, known as the Luce model (Wynne et al., 1992). Like most of the conditioning models, it assumes that the responseeliciting value of a stimulus is increased by a certain amount if the choice of that stimulus is followed by a reward and decreased by a certain amount if it is followed by a penalty. This assumption is of course related to our earlier, simple common-sense use of reward to penalty quotients as approximate estimators of stimulus values. Thus, given a stimulus pair $\mathrm{X}+\mathrm{Y}-$, if the subject chooses $\mathrm{X}+$, the stimulus value will be updated according to $V_{x} \leftarrow V_{x}+\left(V_{x} * \beta_{+}\right)$, where $\beta_{+}$ is an increment parameter related to reward. The value of $\mathrm{Y}$ in this instance remains unchanged according to $V_{y} \leftarrow V_{y}$. If, however, the subject chooses $\mathrm{Y}-$, the value of this stimulus is updated according to $V_{y} \leftarrow V_{y}-\left(V_{y} * \beta_{-}\right)$, where $\beta_{-}$is a parameter related to penalty. In this instance, it is the value of $\mathrm{X}$ that remains unchanged according to $V_{x} \leftarrow V_{x}$. The current values $V_{x}$ and $V_{y}$ in turn determine the percentage with which $\mathrm{X}$ will be chosen in preference to $\mathrm{Y}$ in a given trial according to the simple choice function $P_{x y}=V_{x} * 100 /$ $\left(V_{x}+V_{y}\right)$ that we already know. For a large population a trial with pair $\mathrm{X}+\mathrm{Y}-$ will have the mean effects $V_{x} \leftarrow V_{x}+\left(\beta_{+} * V_{x} * P_{x y}\right) / 100$ and $V_{y} \leftarrow V_{y}-\left(\beta_{-} * V_{y} *\left(100-P_{x y}\right)\right) / 100$ where of course, $100-P_{x y}=P_{y x}$. This basic algorithm can be easily adapted for computer simulations of the training with a given set of premise pairs. The values accruing to the various stimuli at the end of training can be used to predict the preference scores connected with the test pair by using the above mentioned choice function. The preference patterns connected with the $\mathrm{X}+\mathrm{Y}+\mathrm{Z}+$ test triads we mentioned earlier can be derived using the expanded choice function $P_{\mathrm{x}}=V_{x} * 100 /\left(V_{x}+\right.$ $\left.V_{y}+V_{z}\right)$. Since the denominator of this latter formula contains one more term than the former one it yields reduced percentage quotients. This agrees with the empirical finding that $\mathrm{B}+\mathrm{C}+$ $\mathrm{D}+$ triad tests generally yield a weaker preference for B than B $+\mathrm{D}+$ pair tests (Chalmers and McGonigle, 1984; McGonigle and Chalmers, 1992). 
A numerical simulation of von Fersen's pigeon results using the $\mathrm{A}+$ to $\mathrm{E}-$ design involved setting all initial $V_{\mathrm{a}}$ to $V_{\mathrm{e}}$ values equal to 0.1 and running it for approximately the same total number of trials (5000 trials) as in the actual experiment. The parameters $\beta_{+}=0.004$ and $\beta_{-}=0.008$ were found to yield the best match with the final training pair percent accuracies. Table 1 lists the averaged percentage scores obtained across the last 240 (test phase) trials of the simulation. The simulation with the Luce model correctly forecasts transitive choices, but slightly overestimates their magnitude (e.g. 92\% rather than $88 \%$ choices of B). The reasons for the recurring tendency of the Luce model to overestimate transitive choices have been discovered (Siemann, 1994; Siemann and Delius, 1997) and will be considered later. Leaving aside this detail, the capacity of this simple conditioning model to approximately simulate this and many other transitive responding results should suffice to document that the explanation of transitive responding does not require any elaborate cognitive theories.

The success of Luce's model and indeed that of other related, though mostly more complex, conditioning models (Couvillon and Bitterman, 1992; Wynne et al., 1992; Davies et al., 1993, Wynne, 1995; Siemann and Delius, 1997) relates to the fact that the training with the $\mathrm{A}+\mathrm{B}-, \mathrm{B}+\mathrm{C}-$, $\mathrm{C}+\mathrm{D}-, \mathrm{D}+\mathrm{E}-$ scheme right from the outset will not yield anything like the value equalities $V_{\mathrm{b}}=V_{\mathrm{c}}=V_{\mathrm{d}}$ assumed earlier. Instead, it directly produces the value inequalities $V_{\mathrm{b}}>V_{\mathrm{c}}>V_{\mathrm{d}}$ needed for transitive responding. As already pointed out, this is because, contrary to the intention of the training design, the middle stimuli $\mathrm{B}, \mathrm{C}$ and $\mathrm{D}$ are de facto not equally often rewarded

Table 1

Comparison of the empirical percentage accuracies on premise pairs and conclusion pair. During the test phase of von Fersen's (1989) A+ to E- pigeon experiment and the percentage accuracies simulated with Luce's model

\begin{tabular}{llllll}
\hline & $\mathrm{A}+\mathrm{B}$ & $\mathrm{B}+\mathrm{C}-$ & $\mathrm{C}+\mathrm{D}-$ & $\mathrm{D}+\mathrm{E}-$ & $\mathrm{B} \cdot \mathrm{D} \circ$ \\
\hline Predicted & 92 & 86 & 65 & 86 & 92 \\
Observed & 88 & 78 & 67 & 94 & 88 \\
\hline
\end{tabular}

and penalised. A choice/reinforcement biasing/ balancing process that arises during training interferes substantially with the designs intent. It arises because the stimulus value changes caused by the differential reinforcements modify the stimulus choice probabilities and vice-versa, in an interactive fashion that is not intuitively obvious (Siemann et al., 1996b; Siemann and Delius, 1997). Consider first of all the training pair A + $\mathrm{B}-$. Because $\mathrm{A}$ is consistently rewarded it is increasingly chosen, meaning that $\mathrm{B}$ is decreasingly chosen and thus rarely penalised. This in turn encourages choices of $\mathrm{B}$ in the $\mathrm{B}+\mathrm{C}-$ pair, where they are rewarded. Soon choices of $\mathrm{B}$ are overall more often rewarded than penalised. Now consider pair $\mathrm{D}+\mathrm{E}-$. As $\mathrm{E}$ is consistently penalised, D is increasingly chosen and rewarded, which, however, favours penalised choices of $D$ in the $\mathrm{C}+\mathrm{D}-$ pair. Choices of $\mathrm{D}$ are therefore more evenly rewarded and penalised than those of B. In value terms, stimulus B can thus be seen as indirectly gaining from being paired with A, which is always rewarded and stimulus $\mathrm{D}$ as indirectly loosing from being paired with $\mathrm{E}$, which is always penalised; stimulus $\mathrm{C}$ is obviously intermediate in this emerging choice/reinforcement balancing process. The net effect of the process is that the stimulus values are ranked $V_{\mathrm{a}}>V_{\mathrm{b}}>$ $V_{\mathrm{c}}>V_{\mathrm{d}}>V_{\mathrm{e}}$ without intervention of an explicit value transfer mechanism. This, of course, then causes transitive responding (Siemann and Delius, 1997).

It should be obvious that the reinforcement/ choice biasing/balancing mechanism sketched above will be, as already commented, strongly modulated by the relative frequencies of the training pair presentations used and also by the relative effectiveness of the rewards and penalties employed ( $\beta$ parameters in the Luce model). The detailed sequencing of the training pair presentations (random or blocks) can similarly influence the biasing/balancing process. When the pair sequencing during training is drastically differential, for example, by either beginning with the A+ $\mathrm{B}$ - pair and ending with the $\mathrm{D}+\mathrm{E}-$ pair or beginning with the $\mathrm{D}+\mathrm{E}-$ pair and ending with $\mathrm{A}+\mathrm{B}-$ pair, one must reckon with quite pronounced effects. In this context some of the more 


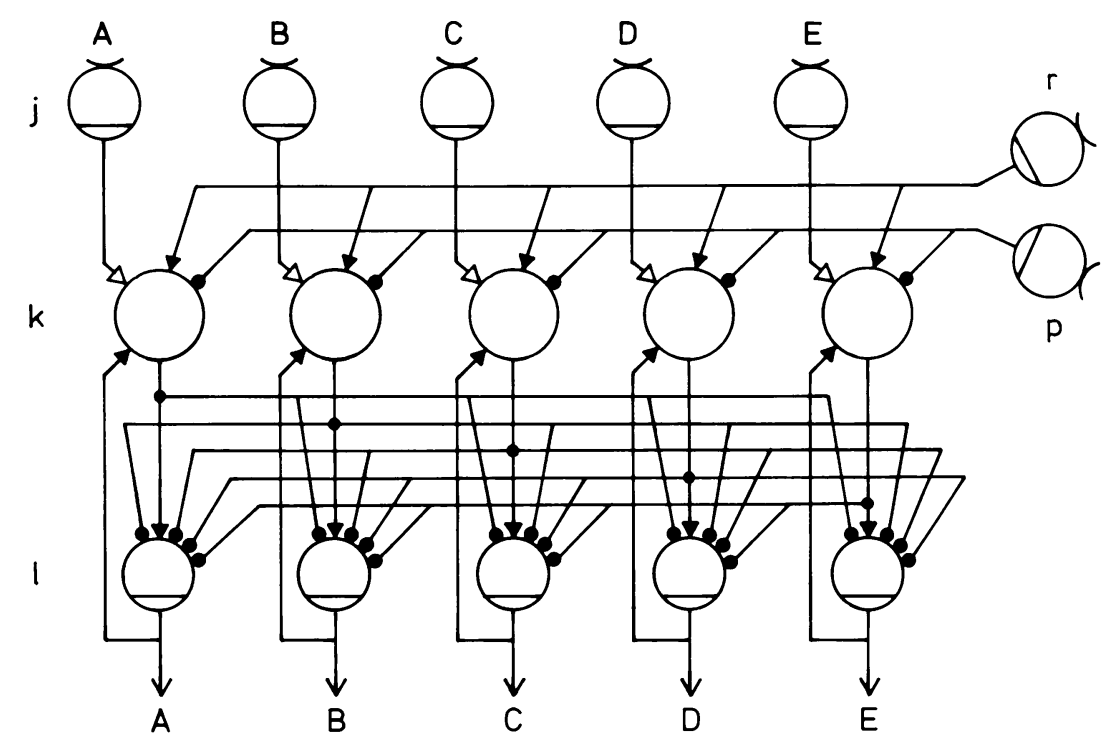

Fig. 3. Adaptive neuronal net for transitive responding. Large circles are neuronal units, arcs designate input units; arrows, output units; bars, units with thresholds. Triangles indicate excitatory connections; circles, inhibitory connections. Open triangles are connections with variable weight (modified from Siemann and Delius, 1997).

complex conditioning models we mentioned earlier can lead to markedly better transitive responding predictions than Luce's model because they differ in the extent that late learning experience can partially overlay the effects of early learning experience (Wynne, 1995, 1997).

Nowadays, an algebraic theory of a conditioning process, such as Luce's model, receives somewhat limited interest unless it can be cast into a neuronal network format. This is not only because connectionism is fashionable, but also because information processing in brains does not really proceed according to algebraic algorithms in any immediate sense and because neuronal networks are arguably far more explicit about the causal flow of events (Churchland and Sejnowski, 1993). Thus, we have recently devised a minimalistic neural network that operates along principles analogous to those of Luce's algebraic model. The network consists of an input $(j)$, a hidden $(k)$ and an output (l) layer (Fig. 3). All three layers contain the same number of units, which must not be less than the number of different stimuli $(i)$ occurring in the premise pairs. The input units $j$ are conceived of as issuing reacting specifically to each of these stimuli and the output units $l$ are con- ceived of as issuing responses specifically directed to each of these stimuli. The $o_{j}$ output of a $j$ unit equals 1 , if the corresponding stimulus is present and 0 if it is not. The input units are connected one-to-one to the intermediate units $k$. The net input component of a $k$ unit due to the input from its $j$ unit is $n_{j, k}=o_{j} * w_{j, k}$. The all-important connection weight $w_{j, k}$ will be specified soon. This net input component persists for a unit time period in the corresponding $k$ unit but also yields an immediate output $o_{k}=n_{j, k}$. The purpose of the transitory buffering of $n_{j, k}$ will become obvious anon.

Each hidden unit $k$ is connected to all output units $l$ so as to form a forward lateral inhibition network. The net input of the $l$ units is thus $n_{l}=\Sigma_{k} o_{k} * w_{k, l}$ with $w_{k, l}=1$ when $k=l$, but $w_{k, l}=$ -1 when $k=l$. The output of each $l$ unit is determined by a threshold function so that either $o_{l}=1$, a response to when stimulus $i=1$ is present, or $n_{k, l}>0$, or $o_{l}=0$, a no-response when $n_{k, l}<0$. This yields the required exclusive response to a particular stimulus on a given trial. Depending on whether the response issued corresponds to a stimulus scheduled to yield a reward or corresponds to a stimulus scheduled to yield a penalty, either input unit $r$ or input unit $p$ is activated with 
a unit time delay so that either $o_{r}=1$ and $o_{p}=0$ or else $o_{p}=1$ and $o_{r}=0$. These outputs are relayed to all hidden layer units (Fig. 3). This corresponds to the widely distributed reinforcement-mediating systems found in vertebrate brains (Rolls, 1975; Delius and Pellander, 1982). The reward and penalty signals contribute to unit time delayed net input components in the hidden $k$ units that amount to $n_{r, k}=w_{r, k} * o_{r}$ and $n_{p, k}=$ $w_{p, k} * o_{p}$ where $w_{r, k}$ and $w_{p, k}$ are equivalent, respectively, to the parameters $\beta_{+}$and $\beta_{-}$of Luce's algebraic model.

Luce's algebraic model specifies that the value increment/decrement due to reward/penalty affects only the stimulus-response link that was instrumental in bringing about either reward or penalty on a particular trial. The network achieves this specific credit assignment by incorporating feedback connections from the output units $l$ to the corresponding units $k$ (Fig. 3). These impinge with a unit time delay on $k$ units according to $n_{l, k}=o_{l}$. This net input component equals 1 in the $k$ units corresponding $k=i$ to the stimulus $i$ responded to, i.e. chosen and equals 0 in all the $k \neq i$ units corresponding to the stimuli not responded to. It acts as a binary gating factor within the hidden $k$ units. In conjunction with the unit time delayed net input components $n_{r, k}, n_{p, k}$ and $n_{j, k}$, specified earlier, it causes a Hebbian-like synaptic weight change (Kandel et al., 1991) affecting the relevant $j$ to $k$ connection according to the update function $w_{j, k} \leftarrow w_{j, k}+\left(n_{j, k} * n_{r, k} * n_{l, k}\right)-$ $\left(n_{j, k} * n_{p, k} * n_{l, k}\right)$. This operation only modifies the weight of the connection and does not lead to any $k$ unit output. The aforementioned buffered net input component self-resets to $n_{j, k}=0$ as soon as the weight adjustment is over. Note that recurrent connectivities of the kind envisaged are quite frequent in real brains (Kandel et al., 1991), but the idea that they may be subserving the allocation of reinforcement effects on stimulus-response links is probably new. Note also that this feedback scheme represents a sort of neurally realistic replacement for the currently fashionable, but neurally unrealistic, error backpropagation scheme (Churchland and Sejnowski, 1993).

As it stands, this neural network, when trained according the usual experimental scheme, very soon produces a perfect $100 \%$ correct performance on the all the training and test pairs. To mimic the circumstance that real organisms always produce a proportion of erroneous choice responses, the network model needs to incorporate noise variables. This agrees with the fact that real neurons are notoriously noisy elements (Kandel et al., 1991). A precise specification of the noise addition is unfortunately a mathematically elaborate affair which we do not attempt to present here. The reader must be content with the claim that, with a suitable noise addition, the network comes close to mimicking the behaviour of the global, stochastic percentage choice function used above with the algebraic version of the Luce model (Siemann and Delius, 1997).

\section{Value transfer revisited}

The theory, or rather theories that we have expounded in the previous section account for transitive responding without appealing to any special value transfer mechanism such as that postulated by von Fersen et al. (1991). The reinforcement/choice biasing/balancing mechanism that is part and parcel of the straightforward conditioning models is demonstrably so powerful in standard transitive responding experiments that value transfer can be estimated to play a minor role at best in bringing about the essential stimulus ranking (Siemann and Delius, 1997). In fact, it is a fair question whether a value transfer mechanism exists at all (Couvillon and Bitterman, 1986). Davis (1992b) noticed that classical conditioning adventitious to the instrumental discrimination learning intended by the experimenters could be the basis of such mechanism. As the subjects learn an instrumental $\mathrm{X}+\mathrm{Y}-$ discrimination, stimulus $\mathrm{X}+$ is obviously increasingly chosen. Stimulus $\mathrm{Y}-$ is thus decreasingly associated with penalties. Instead it can be imagined to function increasingly as a conditioned stimulus that precedes the rewards, i.e. the appetitive unconditioned stimuli occasioned by the responses to $\mathrm{X}+$. It is well known that in a conventional classical conditioning paradigm, where grain access serves as an unconditioned stimulus and an 
initially neutral stimulus serves as a conditioned stimulus, pigeons will begin to issue conditioned response pecking to this latter stimulus (autoshaping; Brown and Jenkins, 1968). That is to say, it seems possible that some classically conditioned response-eliciting value may transfer from stimulus $\mathrm{X}+$ to stimulus $\mathrm{Y}-$ at a late stage of instrumental discrimination learning. Indeed, Biederman et al. (1976) reported long ago that pigeons concurrently trained to discriminate instrumentally a frequently presented $\mathrm{A}+\mathrm{B}-$ stimulus pair and a more rarely presented $\mathrm{C}+$ $\mathrm{D}$ - stimulus pair preferred $\mathrm{B}$ to $\mathrm{D}$ when tested with $\mathrm{B}+\mathrm{D}+$ or $\mathrm{B}-\mathrm{D}-$ test pairs. According to a naive account they should, if anything, have preferred $\mathrm{D}$ because it had been less frequently penalised than $\mathrm{B}$. However, by belonging to the better trained pair $\mathrm{A}+\mathrm{B}-$ the stimulus $\mathrm{B}$ would have benefited more from the aforementioned classical conditioning contingency than the stimulus $\mathrm{D}$ that belonged to the barely trained $\mathrm{C}+$ D - pair.

Siemann et al. (1993) examined the viability of this hypothesis with a special discrimination procedure. Pigeons were conditioned instrumentally to discriminate two target stimuli $\mathrm{A}+$ and $\mathrm{B}-$ that were presented successively in random order behind one transparent key of a conditioning platform. Grain deliveries and time-out served as reinforcers. A successive discrimination procedure was employed because it allowed an uncomplicated addition of separate stimuli as potential recipients of transferred value. Each of the instrumental stimuli was accompanied by a different neutral stimulus $\left(\mathrm{N}_{\mathrm{a}} \circ\right.$ or $\mathrm{N}_{\mathrm{b}}$ ) displayed behind $\mathrm{a}$ neighbouring key. Responses to the latter stimuli had no scheduled consequences. When the pigeons had learned the instrumental discrimination $\mathrm{A}+\mathrm{B}-$ to a criterion of $80 \%$ correct they were tested with intermittent paired $\mathrm{N}_{\mathrm{a}} \circ \mathrm{N}_{\mathrm{b}} \circ$ presentations. As expected according to the value transfer idea, a significant preference for $\mathrm{N}_{\mathrm{a}}$ over $\mathrm{N}_{\mathrm{b}}$ was observed during these test trials. When the reinforcement allocations to the target stimuli were reversed, the preference for the neutral stimuli switched accordingly. Preventing any physical access to the latter stimuli with a transparent key enclosure during training did not alter the subse- quent test preference for the neutral stimulus that had accompanied the rewarded instrumental stimulus (Siemann et al., 1996a). The preferred neutral stimulus has to be viewed as a conditioned stimulus that preceded and accompanied the unconditioned stimulus food brought about by responses to the positive target stimulus. Classical conditioning can thus mediate transfer of response eliciting value from a rewarded target stimulus to an accompanying stimulus.

Siemann and Krug (1996) carried out a further experiment to test the same hypothesis. Simplifying slightly, they first got pigeons to peck a shape $\mathrm{M} \pm$ while rewarding only two-fifths of the responses to it. When the animals responded steadily to this reference stimulus, which was presented alternately on one or the other of two keys, they were additionally and concurrently trained on a simultaneous shape discrimination task $\mathrm{A}+$ B - presented on the same two keys, where responses to shape A were always rewarded and responses to shape B were always penalised. When the discrimination performance on this latter task had not yet quite reached asymptote (less than $90 \%$ correct choices) and then again when it was thoroughly overlearned (more than 95\% correct choices), the pigeons were occasionally tested with interspersed $\mathrm{A} \circ \mathrm{M} \circ$ and $\mathrm{B} \circ \mathrm{M} \circ$ test trials. Not surprisingly, the relative preferences for A over $\mathrm{M}$ increased significantly from $66 \%$ at the early stage of $\mathrm{A}+\mathrm{B}-$ training, to $88 \%$ at the late stage of $\mathrm{A}+\mathrm{B}$-overtraining, this undoubtedly reflecting the continuously increasing value of the normally always rewarded stimulus A. More surprisingly, but in satisfying accordance with the classical conditioning transfer theory sketched above, the relative preference of the normally always penalised, but obviously decreasingly often chosen, stimulus $\mathrm{B}$ over stimulus $\mathrm{M}$ also rose significantly from an early $25 \%$ to a late $39 \%$. Notice however, that the preference increase for $\mathrm{A}$ due to the instrumental contingency, although heading against the asymptote of an outright preference, amounted to $22 \%$ points, but that for B due to the classical conditioning contingency amounted to only $14 \%$ points. This indicates that despite its undoubted reality, the effectiveness of the Pavlovian transfer process is comparatively weak. 
Along the same lines and also using pigeons, Zentall and Sherburne (1994) demonstrated a value transfer effect that accords well with this adventitious classical conditioning mechanism employing a $\mathrm{A}+\mathrm{B}-, \mathrm{C} \pm \mathrm{D}-$ instrumental discrimination design. During training, responses to $\mathrm{A}+$ were always rewarded, whereas responses to $\mathrm{C}$ were only partially rewarded. In tests with a $\mathrm{B} \pm \mathrm{D} \pm$ pair, stimulus $\mathrm{B}$ was definitely preferred. These authors did not yet refer to classical conditioning as the mechanism supporting the value transfer they described. However, in a more recent paper that reports some further confirmatory variations on this dual-discrimination design (Zentall et al., 1996a,b) do so expressly. Meanwhile we have presented formal algebraic and network models that implement a value transfer by incorporating a classical conditioning element into Luce's instrumental conditioning model. These modified models are capable of adequately simulating at least some of the above mentioned results (Siemann et al., 1996a, Siemann and Delius, 1997).

Steirn et al. (1995), however, still attributed transitive responding-like results, obtained with some modifications of the standard transitivity design, to a value transfer mechanism based on the undifferentiated transfer model of von Fersen et al. (1991). We would argue that the appeal to this undifferentiated model is no longer acceptable because, as extensively explained before, its assumption that a $V_{\mathrm{b}}=V_{\mathrm{c}}=V_{\mathrm{d}}$ situation applies before the critical transfer operation takes place, is patently unrealistic. Fittingly, at least some of Steirn et al.'s results are just as well predicted by standard conditioning models without the intervention of any special transfer mechanisms. In the most critical of their experiments, one group of pigeons was trained with a design which progressed successively from the $\mathrm{A}+\mathrm{B}-$ to $\mathrm{D}+$ $\mathrm{E}-$ premise pairs. Another group was trained with a reverse $\mathrm{D}+\mathrm{E}-$ to $\mathrm{A}+\mathrm{B}-$ sequential design. In subsequent tests with a $\mathrm{B} \pm \mathrm{D} \pm$ pair, both groups showed a marked preference for the B stimulus. The authors argued that the results they obtained are explained by Von Fersian value transfer and not by conventional, not really accurately depicted, conditioning mechanisms. How- ever, a closer analysis reveals that two quite different versions of such transfer would have to be advocated, without it being entirely clear why the standard one prescribing transfer from the $\mathrm{X}+$ to the $\mathrm{Y}-$ stimuli would be operative with the forward design and another, non-standard one prescribing transfer from the $\mathrm{Y}-$ to the $\mathrm{X}+$ stimuli would be operative with the backward design. In any case, Wynne (1995); (compare also Wynne, 1997) showed that a conditioning model based on the Rescorla and Wagner (1972) operator and not involving any explicit value transfer element, emulated the results arising with both the premise training conditions. Steirn et al.'s (1995) appeal to value transfer accounts for their results may therefore not be wholly justified (Weaver et al., 1997).

Thus, although we believe that value transfer, in disagreement with Couvillon and Bitterman (1992), is a real phenomenon, in agreement with them and with Wynne $(1995,1997)$, we believe it is not likely to play any decisive role in the emergence of transitive responding within more or less standard non-verbal experimental designs. Simulations with the aforementioned instrumental/classical modification of Luce's model show that the latter component can play only a very minor role in bringing about the $V_{\mathrm{b}}>V_{\mathrm{d}}$ ranking necessary for transitive responding (Siemann and Delius, 1997). This is because the transfer-supporting classical conditioning process, as already stated, only begins to operate sizeably when the instrumental contingencies have already ensured a substantial discrimination within the premise pairs. By then the required value ranking has already arisen through the reinforcement/choice biasing/balancing mechanism embodied in the straight Luce model (or any of the related models) and Pavlovian value transfer can add only little to it.

\section{Conditioned transitivity in humans}

If the transitive responding of animals is due to a simple conditioning process what is the position regarding humans? Insofar as the results obtained from non-verbal transitivity tasks, with children, 
are not particularly different from those obtained with animals (Chalmers and McGonigle, 1984), one may suspect that they are solving them according to similar principles. But what about adult humans? They should surely be expected to apply to such a task the deliberative reasoning considered to be so characteristic of our own species. Siemann (1993) accordingly carried out a series of non-verbal transitive responding experiments with university students. Various transitivity tasks were embedded in simple computer games to ensure optimal motivation. For the first experiment, twenty-four student subjects had to use the arrow-keys of the keyboard to navigate a self-figurine through a castle-like labyrinth displayed on a monitor. (Fig. 4, top). The figurine
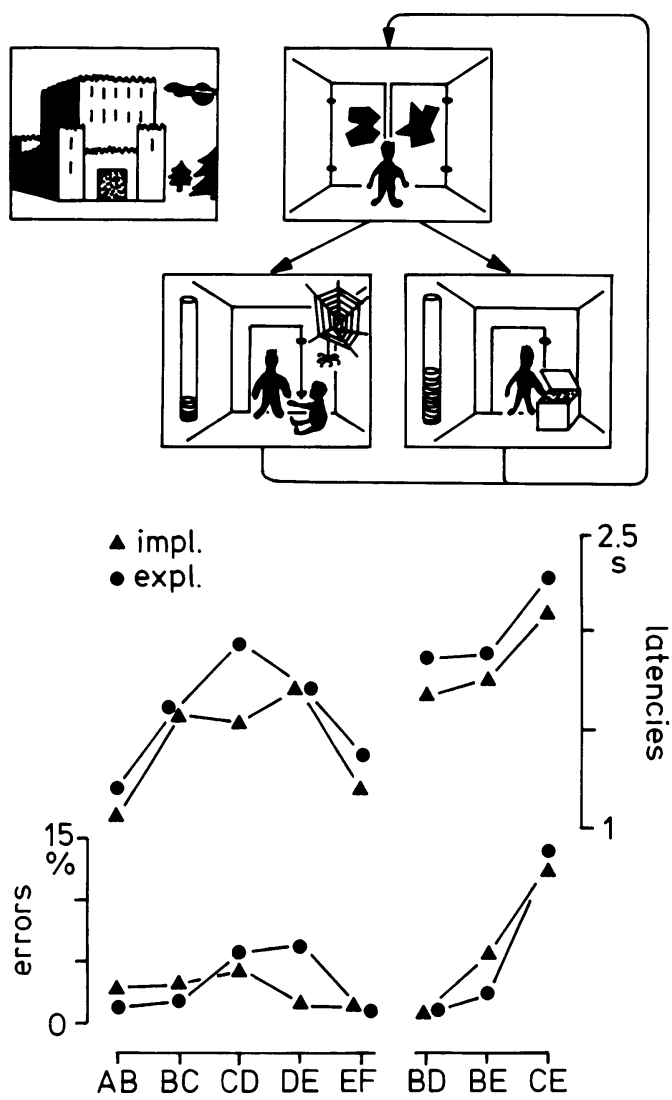

Fig. 4. Top: Procedure used to demonstrate transitive responding in adult humans. Bottom: Discrimination performance of transitive subjects (implicit and explicit) on premise and conclusion pairs (modified from Siemann and Delius, 1993). repeatedly approached pairs of swing-doors. Each door bore one of six different random polygons according to the standard $\mathrm{A}+\mathrm{B}-, \mathrm{B}+\mathrm{C}-$, $\mathrm{C}+\mathrm{D}-, \mathrm{D}+\mathrm{E}-, \mathrm{E}+\mathrm{F}-$ design. If the subject chose the + polygon door, the figurine entered a treasure chamber and picked up a symbolic golden coin from a chest. If the subjects chose the - polygon door, the figurine entered a horror chamber and lost a symbolic coin to a beggar. All subjects learned the premise pairs within an average of 395 trials to a criterion of at least $70 \%$ correct choices. However, only about two-thirds of the subjects responded transitively (at least $70 \%$ transitive choices) when faced with the conclusion tests $\mathrm{B} \circ \mathrm{D} \circ, \mathrm{B} \circ \mathrm{E} \circ$ and $\mathrm{C} \circ \mathrm{D} \circ$ by preferring polygons $\mathrm{B}$ and $\mathrm{C}$ at well above chance levels ( $92 \%$ average preference).

Of the subjects who solved the conclusion tests, only about half were capable of explaining verbally how they had done so. These subjects had obviously garnered explicit knowledge about the structure and the solution of the test. The remaining successful solvers were completely incapable of explaining how they had achieved the transitive test solutions. In other words, they had solved the problem implicitly, without any relevant conscious knowledge. Interestingly, the objective performances indexed by choice accuracies and choice latencies with both the premise and the conclusion polygon pairs were virtually identical (no significant difference) for both the explicit and implicit solvers (Fig. 4, bottom). It looks as if the explicit knowledge about the task structure that some of the subjects had, did not help them in any useful way with the behavioural performance on the transitivity task. Since the choice accuracy results of both the implicit and explicit solvers could be closely simulated with the Luce model, we have reason to believe that both groups were solving the task through a straight conditioning process and that the explicit subjects had merely been able to derive additional but redundant insights, an issue to which we return shortly. Luce's conditioning model, as well as related models and also Staddon's transfer model, completely fail to predict the performance of the subjects who had learned the training pairs but had not solved the test pairs (Siemann and Delius, 1993). We will 
enlarge on this point later, but meanwhile, it is worth noting that we have only occasionally come across this peculiar performance pattern among the approximately three dozen pigeons we have dealt with so far.

When a new group of twenty students dealt with a more concrete version of the same basic task, the proportion of subjects that were ultimately correctly explicit about the task structure increased, but the actual performance was not improved. The realism of the task was increased by transforming it into a game showing six different characters involved in pairwise hierarchy contests, where after a choice the superordinate scolded (speech bubble!) the subordinate who was then seen to run off the monitors face. The proportion of explicit solvers rose significantly from $53 \%$ with the previous task to $80 \%$ with this task. However, the objective performance indexed by average reaction times and average choice accuracies did not change significantly. With the premise pairs these indices amounted to 1.4 and $1.3 \mathrm{~s}$ latencies and 3 and 2\% errors, respectively and with the conclusion pairs they amounted to 1.8 and $1.8 \mathrm{~s}$ latencies and 6 and 3\% errors, respectively (Siemann and Delius, 1996). Similar results were obtained in an experiment where the proportion of subjects who were aware of the problem structure of an identical transitivity task was manipulated in a more direct way. One group of subjects only dealt with the transitivity task, the other had to additionally recall multidigit numbers as a distraction while learning the premise pairs. Proportionally fewer of the solvers were explicit in the latter group than in the former group, but in any case explicit and implicit solvers did not differ in their objective accuracy on test pairs (Keller and Siemann, 1996). In short, human adults do not seem to bring any verbally-based, deliberative reasoning to bear on non-verbal transitivity tasks, even though a variable proportion of subjects acquire knowledge that would in principle allow them to do so. This kind of insight, needless to say, is unpopular with many human cognitive psychologists (Shanks and St. John, 1994), as we are too well aware thanks to several unsympathetic reviews. Regardless, the widespread evidence that implicit knowledge suffices for adequate solutions of many cognitive human feats is very unlikely to go away (Mandler, 1989; Berry, 1991; Reber, 1993).

With the intention of obtaining more insights into the presumed use of logical reasoning by adults, Werner et al. (1992) had earlier tried a transitivity task with two separate item series on adult student subjects. The stimuli were different decorative-geometric shapes which were presented in side-by-side pairs on a projection screen. One of the stimulus series involved six angular shapes $(A-F)$, the other involved six curved shapes $(a-f)$. Two separate training pair series $\mathrm{A}+\mathrm{B}-, \ldots$, $\mathrm{E}+\mathrm{F}-$ and $\mathrm{a}+\mathrm{b}-, \ldots, \mathrm{e}+\mathrm{f}-$ were assembled from these stimuli according to the standard schema. The angular and curved pairs were presented randomly intermixed. Choice of positive or negative shapes on a pair of side-by-side keys yielded, respectively the gain or the loss of a symbolic token. The tokens accumulated were paid out in money at the end of the session. There were within-series $\left(\mathrm{B} \circ \mathrm{D} \circ, \mathrm{B} \circ \mathrm{E} \circ, \mathrm{C} \circ \mathrm{E} \circ, \mathrm{b} \circ \mathrm{d} \circ, \mathrm{b} \circ \mathrm{e}^{\circ}\right.$, $\mathrm{c} \circ \mathrm{e} \circ)$ and between-series $\left(\mathrm{B} \circ \mathrm{e}^{\circ}, \mathrm{b} \circ \mathrm{E} \circ, \mathrm{B} \circ \mathrm{d} \circ, \mathrm{b} \circ \mathrm{D} \circ\right.$, $\left.\mathrm{C} \circ \mathrm{e}^{\circ}, \mathrm{c} \circ \mathrm{E} \circ, \mathrm{C} \circ \mathrm{d} \circ, \mathrm{c} \circ \mathrm{D} \circ\right)$ test pairs. Notice that the across-series test pairs required choices among items that were not logically linked through the training pairs. Nevertheless, even fully explicit solvers showed significant preferences for the absolutely higher ranking items of these mixed pairs. When the task was converted into an almost totally verbal one by using figurines that bore names and differed in height in an obvious, easy to verbalise way, the proportion of explicit solvers rose from 69 to 100\% (Siemann and Delius, 1996). Nevertheless, several subjects again preferred the higher ranking items of the mixed test pairs. Interestingly, the overall objective performance of solver subjects worsened when comparing the non-verbal version and the near-verbal version of the task. While the accuracies remained comparable across the two tasks, with 2 and 3\% errors on premise pairs and 5 and $4 \%$ errors on conclusion pairs, the corresponding reaction times increased significantly from 1.4 to $2.7 \mathrm{~s}$ and from 2.0 to 3.8 $\mathrm{s}$ with the near-verbal task. This increase is very likely due to the fact that the reading and interpretation of the item names in the almost-verbal task required additional time. But the latency 
lengthening illustrates that an intervention of verbally coded operations does not necessarily improve the performance on cognitive tasks.

Using an improved experimental design, Siemann (1993) confirmed that humans, and indeed, pigeons prefer the higher ranking stimuli of mixed pairs. The subjects were trained with six different stimuli arranged into two four-items series that had the end items in common $\mathrm{A}+\mathrm{B}_{1}-, \mathrm{B}_{1}+$ $\mathrm{C}_{1}-, \mathrm{C}_{1}+\mathrm{D}-$ and $\mathrm{A}+\mathrm{B}_{2}-, \mathrm{B}_{2}+\mathrm{C}_{2}-$, $\mathrm{C}_{2}+\mathrm{D}-$. The pigeons were intermittently tested with across-series pairs. The birds did not show any significant preference with $\mathrm{B}_{1} \circ \mathrm{B}_{2} \circ, \mathrm{C}_{1} \circ \mathrm{C}_{2} \circ$ pairs, but they evinced an increasing and eventually significant preference for the $\mathrm{B}$ items when confronted with the $\mathrm{B}_{1} \circ \mathrm{C}_{2} \circ, \mathrm{B}_{2} \circ \mathrm{C}_{1} \circ$ pairs, as the choice accuracy on training pairs $\mathrm{B}_{1}+\mathrm{C}_{1}-$, $\mathrm{B}_{2}+\mathrm{B}_{2}-$ improved. Humans, although tested only at the end of training, yielded an analogous preference pattern. All the above test pairs do not allow any valid conclusions according to the rules of formal logic, but from everyday experience in a probabilistic world the preference pattern found makes perfect sense. Given the inequalities $\mathrm{A}>$ $\mathrm{B}_{1}>\mathrm{C}_{1}>\mathrm{D}$ and $\mathrm{A}>\mathrm{B}_{2}>\mathrm{C}_{2}>\mathrm{D}$ the chances that the approximate equalities $\mathrm{B}_{1} \approx \mathrm{B}_{2}$ and $\mathrm{C}_{1} \approx$ $\mathrm{C}_{2}$ and the inequalities $\mathrm{B}_{1}>\mathrm{C}_{2}$ and $\mathrm{B}_{2}>\mathrm{C}_{1}$ apply are obviously more than even in reality. Interestingly, this is also precisely the preference pattern predicted by Luce's conditioning model (Siemann, 1994).

It is perhaps the occasion to remark briefly on why equalities, as compared to inequalities, play such an insignificant role as relational nexi within the stimulus structures that we consider here. In mathematical logic, for example, equalities are at least as important as inequalities. In fact, Legelli et al. (unpublished) attempted to teach pigeons the premises $\mathrm{A} \pm, \mathrm{B} \pm, \mathrm{A}+\mathrm{C}-, \mathrm{C} \pm \mathrm{D} \pm$ where the symbol \pm indicates that the choices of the relevant stimuli were exactly as often rewarded as they were penalised. The training pair design was intended to implement the relational structure $\mathrm{B}=\mathrm{A}>\mathrm{C}=\mathrm{D}$ with the intention of testing whether the pigeons would draw the corresponding $\mathrm{B}>\mathrm{D}$ conclusion when challenged with the pair $\mathrm{B} \circ \mathrm{D} \circ$. However, regardless of how protracted the training with the equality pairs was, the pigeons persisted in showing idiosyncratic preferences for one or the other of the constituent stimuli. This naturally affected the transitivity testing in spurious and inconsistent ways. We suspect that the ultimate reason is that in the natural world exact equalities are a much more improbable kind of relationship than inequalities and that pigeons can be consequently expected to be evolutionarily biased against accepting them as occasionally existing (Delius, 1994). In any case, we have not yet found a simple and reliable way to convince pigeons lastingly that two stimuli have precisely the same reinforcement value, but it is also the case that we have not yet examined whether humans have an analogous difficulty with conditioned equality relations.

Leaving aside this point, we are generally persuaded that humans and pigeons solve non-verbal transitivity tasks involving inequalities according to the same processing principles and that these principles are well approximated by Luce's conditioning model. Granted, humans tend to learn the premise part of the task faster than pigeons and often end up with an explicit understanding of the tasks structure, something that we obviously cannot establish for pigeons, but neither difference crucially affects how these two species objectively solve the conclusion part of the task. However, it is objectionable whether the non-verbal tasks used were not really challenging the rational competencies of the human species. It is indeed true that most studies on the transitive inference competencies of humans, starting with Piaget's (1921) study, used verbal tasks not incorporating any special premise memorisation stage (Breslow, 1981). So far, no animal transitive responding studies exist that have made use of the quasi-verbal abilities that some non-human individuals have been trained in (for example, pygmy chimpanzees, Pan paniscus, Savage-Rumbaugh and Lewin, 1994; African grey parrot, Psittacus erithacus, Pepperberg, 1994) so that direct comparisons are not possible. It is worth remarking, however, that the usual three-item verbal transitivity tasks used in human research are not really particularly revealing. To answer the question, 'Who is taller, Anna or Celia?' correctly, given the statements, 'Anna is taller than Belle, Belle is 
taller than Celia' all that has to be done is to discover that the attribute taller only attaches exclusively to Anna and not at all to Celia (Smedslund, 1963). For much the same reason the nonverbal task $\mathrm{A}+\mathrm{B}-, \mathrm{B}+\mathrm{C}-, \mathrm{A} \circ \mathrm{C} \circ$ is not considered a valid test for transitive responding in animals (see also later). When human subjects are confronted with a more valid five-term task such as 'Cecil is lighter than Brian, David is lighter than Cecil, Brian is lighter than Andy, Eric is lighter than David' most find it difficult to answer the question 'Who is lighter, David or Brian?' promptly and correctly. This is because the information imparted by the premises exceeds their working memory capacity. Subjects require repeated rehearsals with the premises before they can produce an acceptable level of correct responses (Woocher et al., 1978). This raises the question of whether the rehearsal process does not bring into play a covert learning operation leading to a long-term memory coding. This learning operation could well have similarities with the overt conditioning process described by Luce's, or similar models, an issue that is undoubtedly worth further investigation.

Often, human psychologists tend to be influenced by what subjects report about how they solved a given deductive syllogism and in the present context the reports tend to suggest that they rely on a mental line-like operation much like that which we sketched earlier in this review. Our finding that explicit and implicit subjects do not differ in their objective transitivity performances, however, makes us sceptical about the heuristic worth of such reports. On the other hand, the hypothetical mind's eye may be viewing the ordered associative values (or rather ordered strength of synaptic connections) arising out of our conditioning process much like a mental line representation of the item sequences. Of course, we do not want to deny that on special occasions humans may be using a truly deliberative reasoning to arrive at transitive conclusions, particularly if they can rely on the aid of paper and pencil. One can think of mathematicians having to decide about the monotonic or non-monotonic properties of complex series, or of most people given CCDIIIX $>$ XCCCVI, CCDVII $<$ CCCLII, stretching the principles of Roman numerals somewhat, having to decide whether to insert $<$ or $>$ into CCDLII ? VICCC. But it seems to us that thoughtful transitive inference is much rarer in everyday life than conditioned transitive responding, if only because the former style of deriving conclusions is likely to be a much slower process than the latter form of responding.

\section{Circularity and other non-linearities}

So far we have been concerned only with tasks that have a linear relational structure or at least a predominantly linear structure. How about tasks that involve definitely non-linear relational structures? 'Mary sat to the right of Nancy, Nancy sat to the right of Odile' would not imply that 'Mary sat to the right of Odile' if a small, round table was involved. When Von Fersen (1989) had finished with the transitivity tests described in an earlier section of this review, he retrained his pigeons once more, adding a further training pair. This new pair $\mathrm{F}+\mathrm{X}-$ converted the previously linear structure $\mathrm{X}+\mathrm{A}-, \ldots, \mathrm{E}+\mathrm{F}-$ to a circular structure. The pigeons found this new task exceedingly difficult, although it only involved learning a single additional training pair. All pigeons began to perform worse on the previously well learned premise pairs, one pigeon ceasing to respond altogether, a second one never progressing to a better than chance performance and the remaining two never reaching the criterion of $80 \%$ correct. Though the latter pigeons managed an above chance accuracy on the premise pairs, they no longer evinced transitive responding. Perhaps typically, Wynne (1996) had to use a special sequential training procedure to get pigeons to learn even the minimal three-item $\mathrm{A}+\mathrm{B}-, \mathrm{B}+\mathrm{C}-$, $\mathrm{C}+\mathrm{A}-$ circular design. Davis (1992b), working on rats, added $\mathrm{E}-\mathrm{F}+$ and $\mathrm{F}+\mathrm{A}-$ training pairs to his original $\mathrm{A}+\mathrm{B}-, \ldots, \mathrm{D}+\mathrm{E}-$ scheme and found that his rats ceased to produce transitive choices on the $\mathrm{B} \circ \mathrm{D}$. test pair. Roberts and Phelps (1994) rats, Treichler and Van Tilburgs (1996) macaques and Gillans (1981) chimpanzees also showed performance deteriorations of various kinds following training with similar circular 
designs. Interestingly, De Soto et al. (1965) and Henley et al. (1969) have reported analogous findings concerning humans. Their subjects had to learn verbal statements describing pairwise social relationships. When the relations between the four items that these authors used accorded with a linear series, subjects required little time to learn. With pairs incorporating deviations from the linear structure, the subjects needed longer and made more errors. Interestingly, Staddon's value transfer model and Luce's (and similar) models anticipate serious problems with learning about such structures. We shall return to this shortly but first we pursue a different argument.

The performance differences associated with linear and circular structures motivated Carmesin and Schwegler (1994) to analyse what was needed to encode these and other structures into Rosenblatt perceptrons (elementary parallel networks) and Turing machines (elementary sequential processors). They showed that with either form of processing, an encoding of a purely linear structure was the simpler undertaking and that an encoding of a purely circular structure was relatively more complex (more node connections, more program steps). A certain mixed structure, however, was intermediately complex to encode in the Rosenblatt perceptron and was just as complex to encode as the circular structure in a Turing machine. Siemann and Delius (1994) trained three separate groups of pigeons with five-item discrimination tasks that corresponded to these structures. For one group the reinforcement allocations of all ten pairs that can be assembled with five stimuli accorded with a linear structure: $\mathrm{A}+$ $\mathrm{B}-, \mathrm{B}+\mathrm{C}-, \mathrm{A}+\mathrm{C}-, \mathrm{C}+\mathrm{D}-, \mathrm{B}+\mathrm{D}-$, $\mathrm{A}+\mathrm{D}-, \mathrm{D}+\mathrm{E}-, \mathrm{C}+\mathrm{E}-, \mathrm{B}+\mathrm{E}-, \mathrm{A}+$ $\mathrm{E}-$. For another group the last pair of this list had a reversed reinforcement allocation $(\mathrm{E}+$ $\mathrm{A}-$ ) yielding the neither linear nor circular structure singled out by Carmesin and Schwegler. For a last group, three stimulus pairs had reversed allocations $(\mathrm{E}+\mathrm{A}-, \mathrm{D}+\mathrm{A}-, \mathrm{E}+\mathrm{B}-)$, resulting in a completely circular structure (Fig. 5, top). Within the 2500 training trials that all groups were allowed, the linear group achieved an average performance of $73 \%$ correct choices. The nonlinear structure group only managed a barely
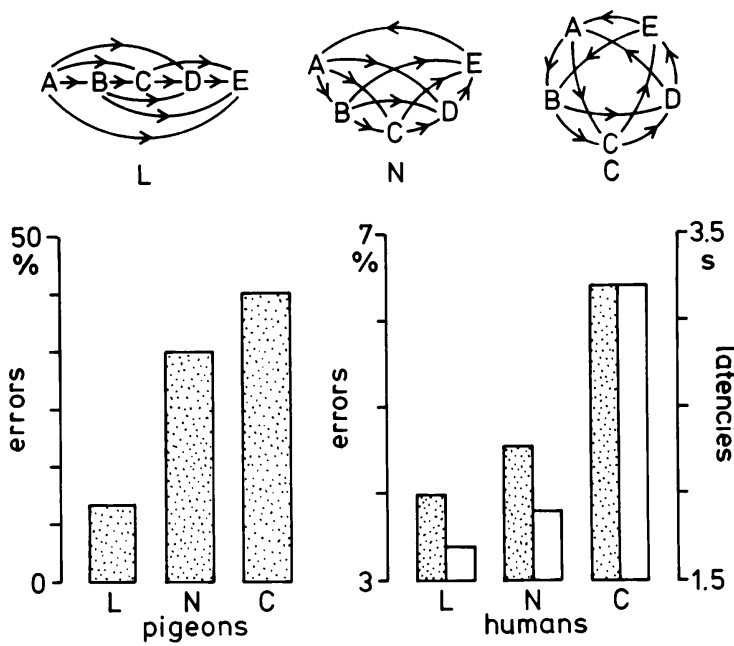

Fig. 5. Top: Linear (L), non-linear (N) and circular (C) relational stimulus structures. The arrow symbols indicate inequalities. Bottom: Terminal performance of pigeons (left, errors) and humans (right, errors: stippled columns, latencies: clear columns) on these three tasks; note the differing error scales (modified from Siemann and Delius, 1994).

above chance performance of $60 \%$ mean correct choices. Of the circular group, two pigeons ceased to respond before completing their training, but even the single pigeon which managed to do so only achieved a near-chance performance of $56 \%$ correct. The results document that linear structures are the easiest to learn for pigeons, circular structures the most difficult and the same seems to be true for adult humans (Fig. 5, bottom). In a parallel experiment, the linear group took a mean 300 trials to discriminate the stimulus pairs to an average $70 \%$ or better criterion and average latencies of $1.7 \mathrm{~s}$. The non-linear group took a mean 510 trials to reach the same criterion with average latencies of $2.0 \mathrm{~s}$. The circular group took a mean 630 trials with two of ten subjects actually not reaching the criterion within a preset limit of 1200 trials, with average latencies of $3.1 \mathrm{~s}$.

The performance advantage of the non-linear task groups over the circular task groups suggests that both humans and pigeons encode relational stimulus structures by means of a process resembling that occurring in parallel networks, rather than in sequential computers. An example of a propositional theory is the artificial intelligence 
model presented by Harris and McGonigle (1994) to account for the transitive responding of squirrel monkeys. It consists of a stack of decision rules that have to be dealt with sequentially when facing an item pair. The particular rule stack that is used by a given individual is thought to be assembled through a trial and error learning process when $\mathrm{s} /$ he deals with the premise pairs. For a given linear transitivity task there is a number of different stacks that will lead to correct conclusions. This is because the stacks can contain both approach rules (if stimulus $\mathrm{X}$ is present, choose $\mathrm{X}$ ) and avoidance rules (if stimulus $\mathrm{Y}$ is present, do not choose Y). The rules of a given stack must be gone through in a prescribed order until a solution for a given stimulus pair is found. The more rules that have to be processed, the greater the chance of errors and the longer the choice latencies. An example of a mixed rule stack that will correctly cope with the conventional $\mathrm{A}+\mathrm{B}-$ ,..., D + E - transitive task is: A present, choose $\mathrm{A}$; E present, avoid E; D present, avoid D; C present, chose $\mathrm{C}$, where the third rule in this case is the one which eventually solves the $\mathrm{B} \circ \mathrm{D}$ 。 test pair. Different rule-stacks can realistically mimic individual performance details when transitivity tasks of conventional design are involved. Interestingly however, the rule-stack modelling has no special problems with circular structures if the circularity operates right from the beginning of training, even though both humans and pigeons clearly have such difficulties. Furthermore, when one attempts to derive predictions for experiments of less conventional design, as for example those involving two independent, or quasi-independent, linear series that were reviewed earlier (Werner et al., 1992; Siemann and Delius, 1996), the stack modelling becomes nearly intractable. In particular, it becomes hard to devise ways by which tall solver-stacks can be assembled through any trialand-error learning process. Propositional models are naturally not as easy to convert into equivalent neural network versions as learning models, which in fact can be viewed as being abbreviated algebraic versions of such networks. Nevertheless, the rule-stack model may be describing what underlies deliberative reasoning solutions of transitivity syllogisms.
However that may be, the performance of the pigeons on all three of the tasks in the Siemann and Delius (1994) study can be simulated quite well with the simple Luce model. But the partially successful performance of humans on the non-linear and circular tasks cannot. Luce's model is based on the assumption that the associative value of a given stimulus increases after reward and decreases after penalty. With the circular task where each stimulus is necessarily about as often rewarded as it is penalised, the model yields virtually identical values for all stimuli and consequently chance level discriminations (Siemann, 1993). It turns out though, that the model can be fairly easily extended to cope not only with learning about the elemental stimuli $\mathrm{X}, \mathrm{Y}$, etc., but also with learning about their configural combinations XY, YZ, etc. That at least some animals and certainly humans can learn about stimuli in a more complex, configural manner was until not so long ago, a much resisted notion but is nowadays a fairly widely accepted fact (Rudy, 1992; Pearce, 1997).

\section{Configural learning model}

The so-called $\varepsilon \kappa$ model of transitive responding accommodates configural learning without foregoing the option of elemental learning (Siemann, 1994; Wynne, 1995, 1996 for a similar configural model). Although it can be easily converted into a neural network model (Siemann and Delius, 1997), here we only summarise the algebraic version. The elemental values of stimuli change just as in Luce's model, but are weighted by a parameter $\varepsilon$. Given pair $\mathrm{X}+\mathrm{Y}-$ and the choice of $\mathrm{X}+$, $V_{x}$ is updated according to $V_{x} \leftarrow V_{x}+\left(V_{x} * \beta_{+} * \varepsilon\right)$; given the choice of $\mathrm{Y}-, V_{y}$ is updated according to $V_{y} \leftarrow V_{y}-\left(V_{y} * \beta_{-} * \varepsilon\right)$. The configural value of stimulus $\mathrm{X}$, given pair $\mathrm{X}+\mathrm{Y}-$ and a choice of $\mathrm{X}+$ is updated according to $V_{x(y)} \leftarrow V_{x(y)}+$ $\left(V_{x(y)} * \beta_{+} * \kappa\right)$, while given the choice of stimulus $\mathrm{Y}$ - the configural value of $\mathrm{Y}$ decreases according to $V_{y(x)} \leftarrow V_{y(x)}+\left(V_{y(x)} * \beta-* \kappa\right)$, where $\kappa$ is a weighting parameter obeying $\varepsilon+\kappa=1$. Notice that whereas the choice of a stimulus $\mathrm{Y}$ out of the pair $\mathrm{Y}+\mathrm{Z}-$ or alternatively out of the pair 
$\mathrm{X}+\mathrm{Y}-$ leads to updates of the same elementary value $V_{y}$, the same choices lead to an update of its configural value $V_{y(z)}$ in one case and its configural value $V_{y(x)}$ in the other case. For a choice, given pair $\mathrm{X}+\mathrm{Y}-$, the corresponding elemental and configural values of stimuli $X$ and $\mathrm{Y}$ are combined according to $W_{x}=V_{x} * V_{x(y)}$ and $W_{y}=V_{y} * V_{y(x)}$ and the combined values entered into the standard percentage choice function $P_{x y}=W_{x} /\left(W_{x}+W_{y}\right) * 100$. The multiplicative, rather than additive combination is preferred for the simple reason that it yields better fitting emulations of real data. With $\varepsilon=1$ and $\kappa=0$ the purely elemental version of the model is virtually equivalent to Luce's model. Accordingly, it copes well with the learning of a linear structure and indeed, given a standard transitivity task, it produces transitive conclusions as soon as the premises are discriminated at an above chance level. However, it will not simulate a successful learning of a circular structure. With $\varepsilon=0$ and $\kappa=1$, the purely configural version of the model can simulate the learning of circular structures producing successful discriminations of the premise pairs, but will not produce transitive responding with conclusion pairs. The reader will remember that earlier we mentioned that a fair proportion of the human subjects participating in the Siemann and Delius (1996) transitivity experiments surprised us by failing to show transitive responding with conclusion pairs, although they had mastered the premise pairs. It can now be assumed that they had operated according to the configural version of the $\varepsilon \kappa$ model, while their transitivity-solving colleagues operated according to a more elemental model with an $\varepsilon \approx 1$. We also commented earlier that Luce's model often tends to overestimate the accuracy of transitive choices regardless of the species involved. With a small $\kappa>0$ value the $\varepsilon \kappa$ model generally produces more precise simulations than the elemental Luce model (Siemann, 1996; Siemann and Delius, 1997). This suggests that even individual subjects who achieve successful transitivity may, to some slight extent, be learning configurally about the training stimuli, an issue to which we shall return shortly.

As already mentioned, we find that although pigeons quite often have difficulties with learning the premise discriminations, once they have learned them they nearly always respond transitively when presented with the test pairs. Four pigeons of Higa and Staddon (1993) series of transitivity experiments are cited as having massively contravened the above generalisation. To expedite the learning of the premise pairs of a standard $\mathrm{A}+\mathrm{B}-$ to $\mathrm{D}+\mathrm{E}-$ schema, these authors employed two different self-adjusting training procedures. In one of these procedures, the premise pair that had been least well discriminated within a given period was repeatedly presented in the following period. In the other procedure, the pair that had been least presented in a given period was presented more often in the following period. However, these procedures were unevenly successful in ensuring a good discrimination across all the training pairs among all pigeons. In fact, only a smaller fraction of the tests connected with satisfactory accuracies on the premise pairs yielded non-transitivity with the $\mathrm{B}-\mathrm{D}-$ conclusion pair. These few instances might indeed be attributable to a predominant configural learning of the training pairs.

Given that pigeons are not particularly prone to learn configurally, it is not surprising that they had markedly greater difficulties than humans with learning the circular relational structure in the Siemann and Delius (1994) study. We surmise that humans are quite inclined to learn configurally about stimuli. Consequently they can learn rather easily about circular structures but can accordingly also easily miss the transitivity associated with linear relational structures. Configural learning may be a characteristic of behaviourally advanced species (in an evolutionary-anagenetical sense: Greenberg, 1995). Although the relevant data are, strictly speaking, too heterogeneous to be properly comparable, it would seem that rats are rather like pigeons, whereas macaques and chimpanzees are more like humans in this respect (Gillan, 1981; Davis, 1992b, Treichler and Van Tilburg, 1996). It is easy to imagine that relatively smaller-brained animals are forced to process perceptual information in an elementary, least redundant and most economic way. On the other hand, comparably largerbrained animals, which certainly have a larger 
absolute number and probably a larger proportion of conditionable, plastic synapses, may be able to afford a configural, somewhat redundant, memory consuming representation (Rensch, 1973; Palm, 1992). Remarkably, these forms of processing seem to be to some extent incompatible, a fact that the $\varepsilon \kappa$ model incorporates by specifying $\varepsilon+$ $\kappa=1$. Subjects, both animal and human, relying on a mainly configural representation of premise pairs seem to largely forego a simultaneous, transitivity-enabling, elemental representation of the same pairs, and vice versa. Humans however, can mix the two strategies in other ways, as exemplified next.

What factors bias humans to learn predominantly either elementally or configurally? Gebhardt and Siemann (1997) investigated the influence of previous experience with linear and circular tasks. One group of subjects first dealt with a standard five-item linear transitivity task $(\mathrm{A}+\mathrm{B}-, \mathrm{B}+\mathrm{C}-, \mathrm{C}+\mathrm{D}-, \mathrm{D}+\mathrm{E}-; \mathrm{B} \circ \mathrm{D} \circ)$. Next, the same subjects were confronted with a fully circular task $(a+b-, b+c-, c+d-$, $\mathrm{d}+\mathrm{e}-, \mathrm{a}+\mathrm{c}-, \mathrm{d}+\mathrm{a}-, \mathrm{e}+\mathrm{a}-, \mathrm{b}+\mathrm{d}-, \mathrm{e}+$ $\mathrm{b}-, \mathrm{c}+\mathrm{e}-)$. Another group of subjects encountered the tasks in reverse order, beginning with the circular structure and ending up with the linear structure. The performance on the $\mathrm{B} \circ \mathrm{D}$ 。 test pair belonging to the linear task was clearly influenced by the task order. Most subjects who began with the circular task chose randomly, or even antitransitively, when eventually faced with this pair, while more than half of the subjects who begun with the linear task chose transitively, preferring stimulus B. Other variables may also be involved in setting the elemental-configural disposition, such as, for example, the figural similarity or the spatial separation between the stimuli, but these factors still require more empirical investigation. However, it is certain that humans, unlike von Fersen's (1989) pigeons, can also learn to handle individual stimulus pairs configurally while processing other pairs within the same task elementally. After learning the training pairs of an $\mathrm{A}+\mathrm{B}-, \ldots, \mathrm{E}+\mathrm{F}-$ task and performing transitively on the $\mathrm{B} \circ \mathrm{D} \circ, \mathrm{B} \circ \mathrm{E} \circ$ and $\mathrm{C} \circ \mathrm{E} \circ$ test pairs, humans subjects additionally learned an $\mathrm{F}+\mathrm{A}-$ pair that closed the sequence to a circular struc- ture. When tested again afterwards, virtually all still preferred those stimuli in test pairs that had served as higher-ranking items in the linear series before. Several subjects were indeed explicit about having registered the extra pair as exceptional and most were not aware of the circular structure that had become operative through the extra training pair. To accommodate this exceptional result, the $\varepsilon \kappa$ model has to be modified to allow locally different $\varepsilon$ and $\kappa$ value mixes (Siemann, 1994).

\section{Evolution of transitive responding}

The results we have reviewed in the preceding sections show that very similar transitive inference-like competencies are present in pigeons, rats, squirrel-monkeys, macaques, chimpanzees, young children and adult humans. This almost unavoidably invites speculation about the evolutionary provenance of this competency. It indicates that general transitive inference capabilities must have an extended evolutionary history, at least among the anagenetically more advanced animals. In a very general way it is probable that transitive inference abilities could contribute to the fitness of virtually every behaving animal that has sufficient spare neural substrate to implement it. As argued in Section 1, the ecosocial environment in which any advanced species operates is replete with objects, events and states, which impinge on their fitness in some attribute-contingent fashion and among which it is potentially adaptive for animals to choose. A complication is that the variations of such stimuli are likely to be arranged in the most arbitrary ways and according to the most complicated patterns within the spatio-temporal volume of the animal's habitat. Consider, for example, a treecreeper (Certhia sp.) that feeds on bark-dwelling bugs. The structure of the prey quality and quantity distribution over tree species, ages, height, health, weathering, frequency, locations, seasons and so forth, that could potentially help this bird to forage optimally can easily boggle the mind of the best ecologist. No doubt, the seeking or avoiding of particular sites according to experienced foraging success is a minimal competence that such a spe- 
cies should be able to bring to bear on the problem. But how much more knowledge can a relatively small-brained animal afford and how much of it would be sensibly useful to it? The ability to rank sites according to prey pay-offs would probably be advantageous. Such ranking would be most informatively done according to absolute prey densities. Indeed, much laboratory evidence suggests that pigeons and rats can at least learn to rank stimuli according to the reward pay-offs that are associated with them (Rensch and Dücker, 1973; Davison and McCarthy, 1988; Belke, 1992). Or, among the several further strategies that are conceivable but can not be detailed here, the ranking may be done according to relative prey pay-offs experienced pairwise. Indeed, this could be a strategy likely to evolve because it does not strain memory capacities and because it agrees with the predominantly relativistic functioning of sensory systems (accurately sensitive to stimulus changes but inaccurately sensitive to stimulus levels; Kandel et al., 1991). In any case, this would involve behavioural competencies akin to those that we have reported in this paper.

It has been shown that by using pairwise experiences of the relative utilities of a collection of stimuli, pigeons can derive such ranking, as judged by transitive responding to new stimulus pairs. However, it is likely that all that is needed to ensure a recall of this ranking is the simple ability to learn to discriminate overlapping pairs of stimuli on a lasting basis. Transitive responding is a competence that does not seem to transcend the availability of simple discriminatory conditioning mechanisms. Accordingly, its essential evolutionary development is likely to have already been achieved when the ability to discriminate reached some mild level of perfection. That implies that any organism capable of reasonable discrimination learning should also show transitive responding when suitably trained and tested. Bees come to mind as a promising candidate species to test this hypothesis, as they have already been shown capable of mastering the threeitem $\mathrm{A}+\mathrm{B}-, \mathrm{B}+\mathrm{C}-$ design (ambiguous cue discrimination: Couvillon and Bitterman, 1986; compare Hall, 1980: pigeons). The capacity for transitive responding could thus be an example for a trait that has primarily evolved by exaptation rather than by adaptation, the former term being a neologism that aptly replaces the older and sometimes misleading term of preadaptation (Gould and Vrba, 1982). That is, it may be a behavioural character that at present, probably has special fitness-promoting functions in at least some species, but which could have evolved among their ancestors under selection pressures that were at least partially different from those that now maintain that competence.

As described, humans and to a much lesser extent pigeons, can display an alternative discrimination learning that is not associated with transitive responding. Indeed, the configural learning that underlies this is likely to be adaptive because it permits a representation of non-linear structures besides linear structures. But we have also shown that everything else being equal, humans and certainly pigeons tend to call preferentially upon the elemental form of discrimination learning that only copes effectively with linear structures, but which includes the bonus of permitting transitive responding. There is also evidence, that during rat and human ontogeny, the capacity for elemental discrimination learning develops before that for configural discrimination learning (Rudy, 1992). By appealing to the onto-phylogenetic recapitulation principle, it may thus be permissible to view the elemental and the configural discrimination learning competencies as correspondingly anagenetically primitive and anagenetically advanced traits.

Piaget (1953) stressed that a so-called reversibility property was the hall-mark of true transitive inference in children. To fulfil that criterion, children had to be able to solve tasks containing opposite nexi such as 'Robin is heavier than Salim, Salim is heavier than Thomas, is Robin lighter than Thomas?'. In a non-verbal task, this reversibility issue can be approximated by training adult humans to learn, for example, that the same visual stimuli belong to a $\mathrm{A}+\mathrm{B}-, \ldots, \mathrm{D}+\mathrm{E}-$ or a $\mathrm{E}+\mathrm{D}-, \ldots, \mathrm{B}+\mathrm{A}-$ premise arrangement depending on which of two colours they are presented. They would be expected to prefer either stimulus B or stimulus D out of the conclusion pair $\mathrm{B} \circ \mathrm{D} \circ$, depending on its colour. This is in fact 
what student subjects are capable of doing, although with some difficulty (Siemann and Gebhardt, 1996). A conditional reversibility competence would seem to be a generally desirable ecological asset for many species. Nevertheless, in a preliminary but extended experiment of a similar design as the above, pigeons appeared to be unable to learn the premise pairs to any adequate and reliable level. But what about non-human primates? McGonigle and Chalmers (1986) summarise results obtained with squirrel-monkeys (and indeed, parallel results obtained with young children) which superficially might be read as demonstrating that they can. However, the report refers only to training and not to test performance results. Furthermore, the stimuli that were used incorporated size differences that gave away their rank relationships in a direct way, a fact that of course weakens an interpretation in terms of monkeys being capable of transitive reversibility. One of Boysen et al.'s (1993) chimpanzees could be thought to have fulfilled the proper reversibility criterion, but in fact the relevant experiment only implemented a sequential reversal from one to the other of the above arrangements, not a simultaneous mastery of both.

The hypothesis that sophisticated cognitive competencies, such as configurality and reversibility, are likely to have principally evolved through selection pressures that arise from a social style of life could be relevant here (Machiavellian intelligence: Whiten and Byrne, 1988). Many animal species, including some anagenetically basal ones, live in social groups characterised by dominance hierarchies that most often but not always, take the form of linear rankings (Chase, 1985; Archer, 1992). Much evidence is extant that individuals acquire rather detailed and flexible knowledge about the dominance relationships that operate in their group (Zayan, 1994). Correct judgement about the rank of partners in such hierarchies translates very directly into fitness gains by reducing the incidence of injuries caused by senseless aggression. The stress reductions that accompany confidence about established dominance hierarchies may also be adaptive (Sapolsky, 1992). But rank knowledge may also be exploited in more complex ways. Macaques, for instance, are known to cunningly divert attacks from a superior monkey to a bystander of lower rank that happens to be a friend and/or relative of the aggressor. Indeed, it seems possible, that in these monkeys, the learning about social hierarchy through self experience is supplemented by learning arising through observation of social encounters of the other monkeys in the group (Seyfarth and Cheney, 1988; Hogue et al., 1996 concerning chickens, Gallus domesticus for experimental evidence on this). Much of the social manoeuvrings that apes (De Waal, 1982) and humans undertake to further their fitness interests are clearly intimately dependant on rank assessments that must often call for transitive responding. These may all be potent evolutionary reasons as to why a basal learning strategy capable of encoding only linear structures, but able to mediate transitive responding, is retained by even evolutionarily advanced species (Von Fersen and Delius, 1992; Siemann, 1996).

Nevertheless, non-linear relational structures are known to occur in nature besides linear structures. They occasionally arise in social hierarchies (de Vries, 1995). It is not surprising, therefore, that humans and probably apes have evolved a strengthened configural learning. Why have pigeons and other comparably basal species only managed to evolve rather inefficient capabilities in this direction? The reason is that, as Carmesin and Schwegler (1994) have made plausible, nonlinear relational structures require a comparatively more complex encoding than linear relational structures. Agreeing with this, we found that the former require a more complex conditioning model than the latter ( $\varepsilon \kappa$ model versus Luce's model). The point is that with non-linear structures the number of pairwise relations that need defining rises sharply with the number of items involved $\left(r=\left(n^{2}-n\right) / 2\right)$, whereas with linear structures the rise is far less pronounced $(r=$ $n-1)$. When a non-linear structure is involved, five items, for example, require the encoding of 10 pairwise relations but 10 items already require the encoding of 45 such relations. When a linear structure is guaranteed, only four and nine pairwise relations are required, respectively. Thus, as the number of items increases, coding parsimony 
may become paramount for reasons of neural economy. In the real world, the utility of items often varies multifariously in a conditional/ configural manner. The specific usefulness of water depends on whether it is clean or not, whether it is close by or not, whether it is in somebody elses territory or not, whether one is thirsty or not, whether ones hide is soiled or not, whether one is hot or not and so forth. As already argued, humans and apes with their large brains seem able to afford the luxury of encoding such special constellations at the cost of some redundancy, whereas pigeons and rats with their much smaller brains (about 800 times smaller) are likely to be pushed for memorial capacity and may only be able to encode the essentials most of the time.

We found that, apart from some disadvantage in premise acquisition and across-task transfer, human adults were practically as efficient in dealing with transitivity tasks when they were unaware (implicit solvers) of their linear structure as when they were aware of it (explicit solvers; Siemann and Delius, 1996; Siemann and Gebhardt, 1996). That raises the question about what the adaptiveness of such explicit understanding might be. We believe that the main answer lies again in the social context. Assuming linguistic competencies, individuals who are able to transmit working knowledge about social hierarchies and strategies to their uninformed friends and relatives would be at a net advantage, in terms of inclusive Darwinian fitness vis-à-vis those who could not (genetically based altruism: Trivers, 1985). The required communication would only be possible if that knowledge were available explicitly. Thus, while implicit transitivity, coded as differentiated preferences for social partners, can be conceived as sufficient for the private domain, it has to be converted into explicit transitivity if it is to be shared through instruction with ones in-group partners (Mandler, 1989). That does not preclude that explicit knowledge coming into play when transitivity tasks present themselves verbally such as in 'Anna is taller than Belle', etc. However, in contrast to authors such as Siegel (1978), we believe that, until proven, one cannot be sure that such knowledge is really essential for their solution. Indeed, it may be a worthwhile research effort to define social and individual transitivity tasks where explicit knowledge could be objectively shown to yield better results than implicit solutions.

\section{Epilogue}

There is no doubt that in the past research about transitive inference has been too much guided by traditions that were conceived and nurtured by strictly principled logicians and rationality-venerating psychologists. We suspect that these traditions have been unduly influenced by the impeccable serial properties of natural numbers where a tidy continuum from $-\infty$ to $+\infty$ guarantees an undisturbed transitivity throughout. Perhaps it is time to turn to the messiness of relational structures in the real world and to the issue of how organisms manage to make use of them to advance their survival and reproduction. For such an enterprise, evolutionary neural networks (Churchland and Sejnowski, 1993) could be the most appropriate theoretical playground and animal experiments in ecosocially natural settings could be the proper testing ground. It may be, for example, that some formally clever procedures to which we expose animals and humans in the laboratory are too far removed from the everyday conditions in which their cognition-supporting neuronal networks are adapted to work efficiently. Consider for example, the studious use of only two reinforcement magnitudes (reward, penalty) when training the discrimination of premise pairs which, strictly speaking, turns the linear structure underlying the transitivity designs into purely illusory relational structures. Transitivity experiments involving truely graded reinforcement allocations to the stimuli (compare Rensch and Dücker, 1973; Boysen et al., 1993; Siemann et al., 1996a; Zentall et al., 1996b), as already suggested, would certainly gain in ecological validity, even though they may lose something in transcending psychological interest. Also, the marked improvement in transitivity acquisition that rats show when the premise items are laid out in a spatial constellation that is congruent, rather than one that is incongruent with the illusory 
linear reinforcement pattern (Roberts and Phelps, 1994), suggests that the representation of relational pattern may be readily linked to cognitive maps (Olton, 1990; Biegler and Morris, 1993). This despite Von Fersen's (1989) failure, described earlier, to demonstrate an influence of more circumscribed spatial cues on the learning of premises and the accuracy of transitivity. It may enable us to come back to the inductive extrapolation problem (the starlings foraging mentioned in Section 1) which started us on the deductive transitivity line of research. We may also be able to tackle the question of how animals deal with the more general hill-climbing problem, i.e. the optimisation task of finding the best ridges in the multidimensional utility landscapes of Section 1. Of course, this is not a new issue (Staddon, 1983), although it is still one that could do with more insights.

\section{Acknowledgements}

We thank the Deutsche Forschungsgemeinschaft for steadfastly supporting our research. We are grateful to Dr L. von Fersen (Nürnberg Zoo) who made several suggestions and to Professors M. Jitsumori (Chiba University) and J. Emmerton (Purdue University) who read a draft critically. We also thank R. Leydel who assisted with manuscript preparation and C. Roberts (Exeter) who helped with language improvement. The contributions of the reviewers are also gratefully acknowledged.

\section{References}

Archer, J., 1992. Ethology and Human Development. Harvester Wheatsheaf, New York.

Belke, T.W., 1992. Stimulus preference and the transitivity of preference. Anim. Learn. Behav. 20, 401-406.

Berry, D.C., 1991. The role of action in implicit learning. Q. J. Exp. Psychol. 43A, 881-906.

Biederman, G.B., Poulos, C.X., Heighinton, G.A., 1976. Paradoxical preference for more frequently occurring negative stimuli and for less frequently occurring positive stimuli as a function of amount of training in simultaneous discrimination learning. Learn. Motiv. 7, 603-613.
Biegler, R., Morris, R.G., 1993. Landmark stability is a prerequisite for spatial but not discrimination learning. Nature 361, 631-633.

Bingman, V.P., 1990. Spatial navigation in birds. In: Kesner, R.P., Olton, D.S. (Eds.), Neurobiology of Comparative Cognition. Erlbaum, Hillsdale, pp. 423-447.

Boysen, S.T., Berntson, G.G., Shreyer, T.A., Quigley, K.S., 1993. Processing of ordinality and transitivity by chimpanzees (Pan troglodytes). J. Comp. Psychol. 107, 208215.

Breslow, L., 1981. Reevaluation of the literature on development of transitive inferences. Psychol. Bull. 89, 325-351.

Brown, P.L., Jenkins, H.M., 1968. Autoshaping of the pigeon's key peck. J. Exp. Anal. Behav. 11, 1-8.

Bryant, P.E., Trabasso, T., 1971. Transitive inferences and memory in young children. Nature 232, 456-458.

Burt, C., 1919. The development of reasoning in schoolchildren. J. Exp. Pedagogy 5, 68-77.

Bush, R.R., Mosteller, F., 1951. A mathematical model for simple learning. Psychol. Rev. 38, 313-323.

Carmesin, H.O., Schwegler, H., 1994. Parallel versus sequential processing of relational stimulus structures. Biol. Cybernet. 71, 523-529.

Chalmers, M., McGonigle, B., 1984. Are children any more logical than monkeys on the five-term series problem?. J. Exp. Child Psychol. 37, 355-377.

Chase, I.D., 1985. The sequential analysis of aggressive acts during hierarchy formation: An application of the jigsaw puzzle' approach. Anim. Behav. 33, 86-100.

Churchland, P.S., Sejnowski, T.J., 1993. The Computational Brain. MIT Press, Cambridge, MA.

Coombs, C.H., Dawes, R.M., Tversky, A., 1970. Mathematical Psychology, an Elementary Introduction. Prentice-Hall, Englewood Cliffs, NJ.

Couvillon, P.A., Bitterman, M.E., 1986. Performance of honeybees in reversal and ambiguous-cue problems: Tests of a choice model. Anim. Learn. Behav. 14, 225-231.

Couvillon, P.A., Bitterman, M.E., 1992. A conventional conditioning analysis of 'transitive inference'. J. Exp. Psychol.: Anim. Behav. Processes 18, 308-310.

Dall, S.R.X., Cuthill, I.C., 1997. Searching in patches by European starlings, Sturnus vulgaris. Behav. Processes 39, $149-159$.

Davies, D.G.S., Staddon, J.E.R., Machado, A., Palmer, R.G., 1993. The process of recurrent choice. Psychol. Rev. 100, $310-320$.

Davis, H., 1992a. Logical transitivity in animals. In: Honig, W.K., Fetterman, J.G. (Eds.), Cognitive Aspects of Stimulus Control. Erlbaum, Hillsdale, pp. 405-429.

Davis, H., 1992b. Transitive inference in rats. J. Comp. Psychol. 106, 342-349.

Davis, H., 1996. Underestimating the rat's intelligence. Cogn. Brain Res. 3, 291-298.

Davison, M., McCarthy, D., 1988. The Matching Law. Erlbaum, Hillsdale.

Dawkins, R., 1969. A threshold model of choice behaviour. Anim. Behav. 17, 120-133. 
Delius, J.D., 1994. Comparative cognition of identity. In: Bertelson, P., Eelen, P., d'Ydewalle, D. (Eds.), International Perspectives on Psychological Science, 1. Erlbaum, Hove, pp. 25-40.

Delius, J.D., Pellander, K., 1982. Hunger dependence of electrical brain self-stimulation in the pigeon. Physiol. Behav. 28, 63-66.

De Soto, C.B., London, M., Handel, S., 1965. Social reasoning and spatial paralogic. J. Pers. Soc. Psychol. 2, 513-521.

De Villiers, P., 1977. Choice in concurrent schedules and a quantitative formulation of the law of effect. In: Honig, W.K., Staddon, J.E.R. (Eds.). Handbook of Operant Behavior. Prentice-Hall, Englewood Cliffs, NJ, pp. 233-287.

de Vries, H., 1995. An improved test of linearity in dominance hierarchies containing unknown or tied relatioships. Anim. Behav. 50, 1375-1389.

De Waal, F.B.M., 1982. Chimpanzee Politics. Jonathan Cape, London.

Emmerton, J., Delius, J.D., 1993. Beyond sensation: Visual cognition in pigeons. In: Zeigler, H.P., Bischof, H.-J. (Eds.). Vision, Brain and Behavior in Birds. MIT Press, Cambridge, MA, pp. 377-390.

Evans, J.S.B.T., Newstead, S.E., Byrne, R.M.J., 1993. Human Reasoning: The Psychology of Deduction. Erlbaum, Hove.

Gebhardt, R.P., Siemann, M., 1997. Processing of linear and nonlinear relationships in human adults (submitted).

Gillan, D.J., 1981. Reasoning in the chimpanzee: II. Transitive inference. J. Exp. Psychol.: Anim. Behav. Processes 7, $150-164$.

Gould, S.J., Vrba, E.S., 1982. Exaptation, a missing term in the science of form. Paleobiology 8, 4-15.

Greenberg, G., 1995. Anagenetic theory in comparative psychology. Int. J. Comp. Psychol. 8, 31-41.

Hall, G., 1980. An investigation of ambiguous-cue learning in pigeons. Anim. Learn. Behav. 8, 283-286.

Harris, M., McGonigle, B., 1994. A model of transitive inference. Q. J. Exp. Psychol. 47B, 310-348.

Henley, N., Horsfall, R., De Soto, C., 1969. Goodness of figure and social structure. Psychol. Rev. 76, 194-204.

Herrnstein, R.J., 1961. Relative and absolute strength of response as a function of frequency of reinforcement. J. Exp. Anal. Behav. 4, 267-272.

Higa, J.J., Staddon, J.E.R., 1993. 'Transitive inference' in multiple conditional discriminations. J. Exp. Anal. Behav. 59, 265-291.

Hogue, M.E., Beaugrand, J.P., Lague, P.C., 1996. Coherent use of information by hens observing their former dominant defeating or being defeated by a stranger. Behav. Processes 38, 241-252.

Huttenlocher, J., 1968. Constructing spatial images: A strategy in reasoning. Psychol. Rev. 75, 550-560.

Johnson-Laird, P.N., 1983. Mental Models. University Press, Cambridge.

Kandel, E.R., Schwartz, J.H., Jessell, T.M. (Eds.), 1991. Principles of Neural Science, 3rd edn. Prentice-Hall, London.

Keller, C., Siemann, M., 1996. Implicit and explicit transitive inferences in human adults in a non-verbal task. In: Elsner,
N., Schnitzler, H.U. (Eds.), Göttingen Neurobiology Report 1996, Thieme, Stuttgart, pp. 780.

Kosslyn, S.M., Thompson, W.L., Kim, I.J., Alpert, N.M., 1994. Topographical representations of mental images in primary visual cortex. Nature 378, 496-498.

Krebs, J.R., Davies, N.B., 1984. Behavioural Ecology: An Evolutionary Approach, 2nd edn. Blackwell, Oxford.

Luce, R.D., 1959. Individual Choice Behavior. Wiley, New York.

Mackintosh, N.J., 1974. The Psychology of Animal Learning. Academic Press, London.

Mandler, G., 1989. Memory: conscious and unconscious. In: Solomon, P.C., Goethals, G.R., Kelley, C.M., Stephens, B.R. (Eds.), Memory: Interdisciplinary Approaches. Springer, New York, pp. 84-106.

McFarland, D., Bösser, T., 1993. Intelligent Behaviour in Animals and Robots. MIT Press, Cambridge, MA.

McGonigle, B., Chalmers, M., 1977. Are monkeys logical?. Nature 267, 694-696.

McGonigle, B., Chalmers, M., 1986. Representation and strategies during inference. In: Myers, T., Brown, K., McGonigle, B. (Eds.), Reasoning and Discourse Processes. Academic Press, New York, pp. 141-164.

McGonigle, B., Chalmers, M., 1992. Monkeys are rational!. Q. J. Exp. Psychol. 45B, 189-228.

Olton, D.S., 1990. Spatial perception: Behavioral and neural analyses. In: Stebbins, W.C., Berkley, M.A. (Eds.), Comparative Perception: Complex Signals. Wiley, New York, pp. 217-244.

Palm, G., 1992. On the information storage capacity of local learning rules. Neural Comput. 4, 703-711.

Pearce, J.M., 1997. Animal Learning and Cognition, An Introduction, 2nd edn. Psychology Press, Hove.

Pepperberg, I.M., 1994. Numerical competence in an African Gray Parrot (Psittacus erithacus). J. Comp. Psychol. 108, 36-44.

Piaget, J., 1921. Une forme verbal de la comparison chez l'enfant (A verbal form of comparisons in the child). Arch. Psychol. 1921, 141-172.

Piaget, J., 1953. Logic and Psychology, 1st edn. University Press, Manchester.

Reber, A.S., 1993. Implicit Learning and Tacit Knowledge. Clarendon Press, Oxford.

Rensch, B., 1973. Gedächtnis, Begriffsbildung und Planhandlung bei Tieren (Memory, Concept Formation, and Planned Behaviour in Animals). Parey, Berlin.

Rensch, B., Dücker, G., 1973. Discrimination of patterns indicating four and five degrees of reward by birds. Behav. Biol. 9, 279-288.

Rescorla, R.A., Wagner, A.R., 1972. A theory of Pavlovian conditioning: Variations in the effectiveness of reinforcement and nonreinforcement. In: Black, A.H., Prokasy, W.F. (Eds.), Classical Conditioning II: Current Research and Theory. Appleton-Century-Crofts, New York, pp. 6499.

Roberts, W.A., Phelps, M.T., 1994. Transitive inference in rats: A test of the spatial coding hypothesis. Psychol. Sci. 5, 368-374. 
Rolls, E.T., 1975. The Brain and Reward. Pergamon, Oxford.

Rudy, J.W., 1992. Development of learning: From elemental to configural associative networks. Adv. Infancy Res. 7, 247-289.

Sapolsky, R.M., 1992. Stress, the Aging Brain, and the Mechanisms of Neuron Death. MIT Press, Cambridge, MA.

Savage-Rumbaugh, E.S., Lewin, R., 1994. Kanzi: The Ape at the Brink of the Human Mind. Wiley, New York.

Seyfarth, R.M., Cheney, D.L., 1988. Do monkeys understand their relations? In: Byrne, R.W., Whiten, A. (Eds.), Machiavellian Intelligence. Social Expertise and the Evolution of Intellect in Monkeys, Apes and Humans. Clarendon Press, Oxford, pp. 69-84.

Shanks, D.R., St. John, M.F., 1994. Characteristics of dissociable human learning systems. Behav. Brain Sci. 17, 367447.

Siegel, L.S., 1978. The relationship of language and thought in the preoperational child: A reconsideration of nonverbal alternatives to Piagetian tasks. In: Siegel, L.S., Brainerd, C.J. (Eds.), Alternatives to Piaget: Critical Essays on the Theory. Academic Press, New York, pp. 43-68.

Siemann, M., 1993. Transitive Inferenz: Experimentelle Untersuchung einer kognitiven Leistung (Transitive Inference: Experimental Investigation of a Cognitive Performance). PhD Thesis, Universität Konstanz.

Siemann, M., 1994. Überprüfung einfacher Modelle zum transitiven Schlußfolgern bei nonverbaler Aufgabenstellung (Test of simple models of transitive deduction with nonverbal tasks). Z. Exp. Angew. Psychol. 41, 584-616.

Siemann, M., 1996. Transitive Inferenz bei nonverbaler Präsentationsform, ein Überblick (Transitive inference using a nonverbal form of presentation, a review). Z. Psychol. 204, 233-259.

Siemann, M., Daniel, D., Dombrowski, D., Delius, J.D., 1993. Value transfer in pigeon conditioning. In: Elsner, N., Heisenberg, M. (Eds.), Gene, Brain and Behavior. Thieme, Stuttgart, p. 856.

Siemann, M., Delius, J.D., 1993. Implicit deductive responding in humans. Naturwissenschaften 80, 364-366.

Siemann, M., Delius, J.D., 1994. Processing of hierarchic stimulus structures has advantages in humans and animals. Biol. Cybernet. 71, 531-536.

Siemann, M., Delius, J.D., 1996. Influences of task concreteness upon transitive responding in humans. Psychol. Res. $59,81-93$.

Siemann, M., Delius, J.D., 1997. Learning and neural network models for transitive and nontransitive responding in humans and animals. Eur. J. Cogn. Psychol. (in press).

Siemann, M., Delius, J.D., Dombrowski, D., Daniel, S., 1996a. Value transfer in pigeon discrimination learning. Psychol. Rec. 46, 707-728.

Siemann, M., Delius, J.D., Wright, A.A., 1996b. Transitive responding in pigeons: Influences of stimulus frequency and reinforcement history. Behav. Processes 37, 185-195.

Siemann, M., Gebhardt, R.P., 1996. Einflu $\beta$ der Instruktion und Aufgabenkomplexität auf transitive Entscheidungen (Influence of instructions and task complexity on transitive decisions). Z. Exp. Psychol. 43, 435-460.
Siemann, M., Krug, I., 1996. Further evidence for a value transfer in pigeons. In: Elsner, N., Schnitzler, H.U. (Eds.), Proc. Göttingen Neurobiology Meeting, Thieme, Stuttgart, p. 782 .

Smedslund, J., 1963. Development of concrete transitivity of length in children. Child Dev. 34, 389-405.

Spetch, M.L., 1990. Further studies of pigeons' spatial working memory in the open-field task. Anim. Learn. Behav 18, $332-340$.

Staddon, J.E.R., 1983. Adaptive Behavior and Learning. University Press, Cambridge.

Steirn, J.N., Weaver, J.E., Zentall, T.R., 1995. Transitive inference in pigeons: Simplified procedures and a test of value transfer theory. Anim. Learn. Behav. 23, 76-82.

Tinbergen, N., 1951. The Study of Instinct. Oxford University Press, Oxford.

Trabasso, T., Riley, C.A., 1975. The construction and use of representations involving linear order. In: Solso, R.L., (Ed.). Information Processing and Cognition. The Loyola Symposium, Erlbaum, New York, pp. 381-410.

Treichler, F.R., Van Tilburg, D., 1996. Concurrent conditional discrimination tests of transitive inference by macaque monkeys: List linking. J. Exp. Psychol.: Anim. Behav. Processes 22, 105-117.

Trivers, R., 1985. Social Evolution. Benjamin/Cummings, Menlo Park.

von Fersen, L., 1989. Kognitive Prozesse bei Tauben (Columba livia) (Cognitive Processes in Pigeons (Columba livia)). Pfaffenweiler: Centaurus.

von Fersen, L., Delius, J.D., 1992. Schlußfolgerndes Denken bei Tauben (Deductive Thinking in Pigeons). Spektrum Wiss. 7, 18-22.

von Fersen, L., Wynne, C.D.L., Delius, J.D., Staddon, J.E.R., 1991. Transitive inference formation in pigeons. J. Exp. Psychol.: Anim. Behav. Processes 17, 334-341.

Weaver, J.E., Steirn, J.N., Zentall, T.R., 1997. Transitive inference in pigeons: Control for differential value transfer. Psychonomic Bull. Rev. 4, 113-117.

Werner, U., Köppl, U., Delius, J.D., 1992. Transitive Inferenz bei nichtverbaler Aufgabendarbietung (Transitive inference with nonverbal task presentation). Z. Exp. Angew. Psychol. 39, 662-693.

Whiten, A., Byrne, R.W., 1988. The Machiavellian intelligence hypotheses: editorial. In: Byrne, R.W., Whiten, A. (Eds.), Machiavellian Intelligence. Social Expertise and the Evolution of Intellect in Monkeys, Apes and Humans. Clarendon Press, Oxford, pp. 1-10.

Wilkie, D.M., Carr, J.A.R., Galloway, J., Parker, K.J., Yamamoto, A., 1996. Some characteristics of spatial associative memory in the pigeon (Columba livia). Behav. Processes 38, 67-76.

Wilkie, D.M., Willson, R.J., 1995. More evidence of robust spatial associative memory in the pigeon (Columba livia). Anim. Learn. Behav. 23, 69-75.

Woocher, F.D., Glass, A.L., Holyoak, K.J., 1978. Positional discriminability in linear orderings. Mem. Cognit. 6, 165173. 
Wynne, C.D.L., 1995. Reinforcement accounts for transitive inference performance. Anim. Learn. Behav. 23, 207217.

Wynne, C.D.L., 1996. Transverse patterning in pigeons. Behav. Processes 38, 119-130.

Wynne, C.D.L., 1997. Pigeon transitive inference: Tests of simple accounts of a complex performance. Behav. Processes 39, 95-112.

Wynne, C.D.L., Von Fersen, L., Staddon, J.E.R., 1992. Pigeons' inferences are transitive and the outcome of elementary conditioning principles: A response. J. Exp. Psychol.: Anim. Behav. Processes 18, 313-315.
Zayan, R., 1994. Mental representations in the recognition of conspecific individuals. Behav. Processes 33, 233-246.

Zentall, T.R., Sherburne, L.M., 1994. Transfer of value from $\mathrm{S}+$ to $\mathrm{S}-$ in a simultaneous discrimination. J. Exp. Psychol.: Anim. Behav. Processes 20, 176-183.

Zentall, T.R., Sherburne, L.M., Roper, K.L., Kraemer, P.J., 1996a. Value transfer in a simultaneous discrimination appears to result from within-event Pavlovian conditioning. J. Exp. Psychol.: Anim. Behav. Processes 22, 68-75.

Zentall, T.R., Weaver, J.E., Sherburne, L.M., 1996b. Value transfer in concurrent-schedule discriminations by pigeons. Anim. Learn. Behav. 24, 401-409. 